\title{
Discrete Pools of Oligomeric Amyloid- $\beta$ Track with Spatial Learning Deficits in a Mouse Model of Alzheimer Amyloidosis
}

Angie C.A. Chiang, ${ }^{*}$ Stephanie W. Fowler, ${ }^{*}$ Rohit Reddy, ${ }^{* \dagger}$ Olga Pletnikova, ${ }^{\ddagger}$ Juan C. Troncoso, ${ }^{\ddagger}$ Mathew A. Sherman, Sylvain E. Lesne, ${ }^{\S}$ and Joanna L. Jankowsky*

From the Departments of Neuroscience* and Neurology and Neurosurgery , Huffington Center on Aging, Baylor College of Medicine, Houston, Texas; the Department of Cognitive Science, ${ }^{\dagger}$ Rice University, Houston, Texas; the Division of Neuropathology, ${ }^{\ddagger}$ Department of Pathology, Johns Hopkins University School of Medicine, Baltimore, Maryland; and the Department of Neuroscience, ${ }^{\S}$ N. Bud Grossman Center for Memory Research and Care, Institute for Translational Neuroscience, University of Minnesota, Minneapolis, Minnesota

Accepted for publication November 2, 2017.

Address correspondence to Joanna L. Jankowsky, Ph.D., Baylor College of Medicine, BCM295, One Baylor Plaza, Houston, TX 77030. E-mail: jankowsk@bcm.edu.

\begin{abstract}
Despite increasing appreciation that oligomeric amyloid- $\beta(A \beta)$ may contribute to cognitive decline of Alzheimer disease, defining the most critical forms has been thwarted by the changeable nature of these aggregates and the varying methods used for detection. Herein, using a broad approach, we quantified $A \beta$ oligomers during the evolution of cognitive deficits in an aggressive model of $A \beta$ amyloidosis. Amyloid precursor protein/tetracycline transactivator mice underwent behavioral testing at 3, 6, 9, and 12 months of age to evaluate spatial learning and memory, followed by histologic assessment of amyloid burden and biochemical characterization of oligomeric $A \beta$ species. Transgenic mice displayed progressive impairments in acquisition and immediate recall of the trained platform location. Biochemical analysis of cortical extracts from behaviorally tested mice revealed distinct age-dependent patterns of accumulation in multiple oligomeric species. Dot blot analysis demonstrated that nonfibrillar $A \beta$ oligomers were highly soluble and extracted into a fraction enriched for extracellular proteins, whereas prefibrillar species required high-detergent conditions to retrieve, consistent with membrane localization. Low-detergent extracts tested by $82 \mathrm{E} 1$ enzyme-linked immunosorbent assay confirmed the presence of bona fide $A \beta$ oligomers, whereas immunoprecipitation-Western blotting using high-detergent extracts revealed a variety of SDS-stable low-n species. These findings show that different $A \beta$ oligomers vary in solubility, consistent with distinct localization, and identify nonfibrillar $A \beta$ oligomer-positive aggregates as tracking most closely with cognitive decline in this model. (Am J Pathol 2018, 188: 739-756; https://doi.org/10.1016/j.ajpath.2017.11.011)
\end{abstract}

A topic of ongoing debate in Alzheimer disease (AD) research is the extent to which different amyloid- $\beta(\mathrm{A} \beta)$ species contribute to disease onset ${ }^{1,2}$ and whether these conformations continue to play a role once other features of neuropathology, such as neurofibrillary tangles and frank neurodegeneration, become prominent. ${ }^{3}$ Although early histologic studies found strong correlation between amyloid load and dementia severity, ${ }^{4}$ subsequent reports indicated that other markers were more strongly predictive of cognitive decline. ${ }^{5-8}$ Newer hypothetical models of disease progression derived from biomarker and neuroimaging studies suggest that amyloid burden plateaus long before memory deficits emerge, ${ }^{9,10}$ supporting the idea that $A \beta$ accumulation may be necessary, but not sufficient, for AD. These findings have led to the sense that $\mathrm{A} \beta$ contributes little to cognitive decline with clinical

\footnotetext{
Supported by NIH grants DP2 OD001734 (J.L.J.), R01 NS092615 (J.L.J.), T32 AG000183 (A.C.A.C.), R00 AG031293 (S.E.L.), R01 NS033249 (S.E.L.), R01 AG044342 (S.E.L.), P50AG005146 (J.C.T.), and AG033655 (J.C.T.), the Robert A. and Rene E. Belfer Family Foundation (J.L.J.), the Gates Millennium Scholarship (A.C.A.C.), the University of Minnesota Medical Foundation startup funds (S.E.L.), and the BrightFocus Foundation (J.C.T.).

A.C.A.C. and S.W.F. contributed equally to this work.

Disclosures: None declared.
} 
progression of the disease. However, this view is complicated by the presence of multiple concurrent alterations at later stages of disease that prevent any clear attribution.

Simpler model systems with fewer coincident pathologies may offer a useful platform for testing whether prolonged accumulation of $A \beta$ is capable of promoting progressive cognitive dysfunction and, if so, which $\mathrm{A} \beta$ species contribute to this effect. In addressing this question, the limited pathologic progression of most amyloid precursor protein (APP) transgenic models becomes advantageous. Lacking neurofibrillary tangle pathology or significant neurodegeneration, transgenic mice carrying disease-associated variants of APP have been proposed to best model preclinical AD before the onset of overt cognitive symptoms. ${ }^{11}$ Yet, even at this stage of the human disease, emerging evidence suggests that cognitively normal subjects show significant inverse correlations between the amount of amyloid detected by neuroimaging and multiple indicators of neural function, including processing speed, neural activation in prefrontal cortex, verbal fluency, and episodic and working memory. ${ }^{12-19}$ The presence of amyloid in these patients is likely accompanied by multiple other $A \beta$ species that cannot yet be measured, but which likely contribute to neuronal dysfunction. We wondered whether a particularly aggressive mouse model for this preclinical stage might allow us to study the relationship between amyloid load, oligomeric $A \beta$ species, and cognitive performance across the full spectrum of human amyloid pathology. Herein, we establish the correspondence between our mouse model and human Consortium to Establish a Registry for Alzheimer Disease (CERAD) staging, and we use this framework to dissect the evolution of $A \beta$ species in relation to the progressive failure of cognitive behavior.

\section{Materials and Methods}

\section{Mice}

The tet-responsive APP transgenic line 102 (tetO-APPswe/ ind 102; 034845-JAX ${ }^{20}$; The Jackson Laboratory, Bar Harbor $\mathrm{ME}$ ) and the tetracycline-transactivator (TTA) line B CaMKII $\alpha$-tTA (3010; The Jackson Laboratory ${ }^{21}$ ) were independently backcrossed to $\mathrm{C} 57 \mathrm{BL} / 6 \mathrm{~J}$ for $>25$ generations before being intercrossed for these studies. The resulting double-transgenic male offspring were then mated with wildtype FVB females to produce experimental cohorts on an FVBB6 $F_{1}$ background. This breeding scheme yielded a large number of offspring on a stable $F_{1}$ genetic background with better behavioral performance than the C57BL/6J parental strain. ${ }^{22}$ All transgenic mice were heterozygous for one or both transgenes (no homozygotes were produced), and animals of both sexes were included in all cohorts.

\section{Doxycycline Administration}

All mice used in this study were raised on doxycycline to suppress transgene expression during postnatal development. We have previously shown this strategy to ameliorate locomotor hyperactivity and normalize body weight of double-transgenic animals, permitting reliable cognitive testing. ${ }^{23}$ Offspring began to receive doxycycline 1 to 3 days after birth by placing nursing mothers on medicated chow, formulated to contain 50 to $100 \mathrm{mg} / \mathrm{kg}$ doxycycline in a breeder diet chow [Purina Mills TestDiet, St. Louis, MO (5APL) or Bio-Serve, Flemington, NJ (F6712)]. After weaning, mice were changed to doxycycline chow formulated in a standard diet until 6 weeks of age [Purina Mills TestDiet (5SBA) or Bio-Serve (F6619)]. After 6 weeks, all mice were maintained on standard diet chow until harvest.

\section{Behavioral Assays}

Behavioral testing began at $4.5,7.5,10.5$, or 13.5 months of age, following 3, 6, 9, or 12 months of APP overexpression. Naïve cohorts were used for each time point and were harvested after behavioral testing, as described later. Animals were handled for 3 days before the start of behavioral testing. Locomotor activity was assessed on day 1 , followed by Morris water maze training on days 2 to 10 (3- and 6-month cohorts) or days 2 to 13 (9- and 12-month cohorts) and visible platform testing on day 12 (or 15). All animal experiments were reviewed and approved by the Baylor College of Medicine (Houston, TX) Institutional Care and Use Committee.

\section{Open Field Assessment}

Locomotor activity was assessed in white acrylic open-top boxes $(46 \times 46 \times 38 \mathrm{~cm})$ in a room lit by indirect white light. Activity was recorded for 30 minutes and analyzed using the ANY-maze Video Tracking System version 4.99v (Stoelting Co, Wood Dale, IL).

\section{Morris Water Maze}

Morris water maze (MWM) testing was conducted, as previously described, ${ }^{24}$ using a circular tank measuring 58 $\mathrm{cm}$ high and $122 \mathrm{~cm}$ in diameter, filled to $20 \mathrm{~cm}$ from the top of the tank with water made opaque using nontoxic white paint. Water temperature was maintained between $21^{\circ} \mathrm{C}$ and $23^{\circ} \mathrm{C}$. The room was lit with indirect white light, and trials were recorded and tracked using ANY-maze Video Tracking System.

Before the start of acquisition training, mice received 1 day of training in a straight swim channel to acclimate them to the water and check for motor deficits. Mice underwent eight trials with a 15-minute intertrial interval in a channel constructed of white acrylic and measuring $107 \times 56 \times 14 \mathrm{~cm}$ that was placed in the center of a pool. Visible cues were removed from the room during straight swim shaping trials. Mice were allowed 60 seconds to reach a submerged platform on the opposite side of the channel. Mice that failed to reach the platform were guided to the location by the experimenter. Mice were allowed to stay on the platform for 15 seconds 
before being removed from the water, dried, and returned to their home cage under an infrared lamp between trials.

Acquisition training in the MWM consisted of four trials per day with a 15-minute intertrial interval. Each training session ended with a short-term memory probe. A square platform $(10 \times 10 \mathrm{~cm})$ covered in nylon mesh for traction was located $1 \mathrm{~cm}$ below the surface in the northeast quadrant of the maze, halfway between the side and the center of the pool. Mice were placed in the maze facing the wall at each of four cardinal start locations and allowed 60 seconds to locate the hidden platform. As with straight swim, animals that failed to locate the platform in the allotted time were gently guided there by the experimenter. Mice were allowed to stay on the platform for 15 seconds before being returned to their home cage between trials. After the four training trials, the platform was removed from the maze for an immediate probe trial to test short-term memory (STM). Animals were placed in the tank halfway between the cardinal points (southwest, northwest, southeast, northeast) and allowed 45 seconds to navigate the maze. Proximity to target, percentage time, and percentage path spent in each quadrant were calculated along with the number of times the animal crossed the platform location compared with the other three potential platform locations (in the southwest, northwest, and southeast quadrants). Mice were trained to a performance criterion during STM probe trials of $\geq 35 \%$ path in the correct quadrant and at least $40 \%$ of total platform crossings over the correct site compared with other possible platform locations. Mice were trained for a maximum of 8 (3- and 6-month cohorts) or 10 (9and 12-month cohorts) days. When mice reached criterion, they were retired from further MWM training and given a final long-term memory probe the following day.

\section{Search Strategy Analysis}

The swim path for each training trial was plotted using ANY-maze Video Tracking System software version 4.99v. At the conclusion of testing, a single unbiased observer (R.R.), blinded to mouse genotype and age, categorized each trial according to the predominant search strategy used during the trial. Search strategies were broadly scored as spatial, nonspatial systemic, or repetitive looping, on the basis of a classification scheme previously described by Brody and Holtzman. ${ }^{25}$ Strategies within each category were further classified as spatial direct (swimming directly to the platform), focal correct (concentrating swim path in the target quadrant), random (no discernible strategy or crisscrossing the pool more than five times), focal incorrect (concentrating swim path in an incorrect quadrant), scanning (crisscrossing the pool two to five times), peripheral looping (thigmotaxic behavior), chaining (swimming around the pool at a distance approximately equal to that of the potential platform locations), or circling (swimming in small concentric circles). To compare search strategy use between amyloid-bearing APP/TTA mice and controls, the eight individual search strategies were combined into broad search categories (spatial, nonspatial, and repetitive looping) and the number of mice was quantified using each strategy on day 3 of training - the last day of training before most controls met criteria and were retired from further testing. Search strategies used by APP/TTA mice were compared across time points to determine whether search strategy use changed with amyloid accumulation.

\section{Visible Platform Testing}

After completion of MWM testing, the room was prepared for visible platform testing by removing all prominent cues from the walls. The submerged platform was replaced with an alternative bearing a central pole that protruded $10 \mathrm{~cm}$ from the water surface and was marked with black tape. The platform was moved in pseudorandom order between the four quadrant locations, and animals were placed into the pool directly opposite the platform facing the wall. Animals were given 60 seconds to locate the platform and were returned to their home cage for 15 minutes between trials. Animals had to remain on the platform for at least 5 seconds to count as a successful trial; however, on some trials, animals reached the platform quickly but did not stay put. Animals were, therefore, required to locate and remain on the platform for three of the four trials; animals that failed two or more trials were excluded ( 9 months, one APP/TTA; 12 months, one TTA and one APP/TTA).

\section{Mouse Brain Harvest}

One week after behavioral testing was completed, mice were sacrificed by sodium pentobarbital overdose and transcardially perfused with ice-cold phosphate-buffered saline containing $10 \mu \mathrm{g} / \mathrm{mL}$ heparin. Brains were removed and hemisected along the midline. One hemisphere was dissected to isolate the cortex and hippocampus, which were snap frozen for biochemistry, and the other hemisphere was immersion fixed in $4 \%$ paraformaldehyde at $4^{\circ} \mathrm{C}$ for 48 hours. Brains were cryoprotected in $30 \%$ sucrose at $4^{\circ} \mathrm{C}$. Tissue was divided into sections ( $35 \mu \mathrm{m}$ thick) in the sagittal plane using a freezing sliding microtome, then stored in cryoprotectant $(0.1 \mathrm{~mol} / \mathrm{L}$ phosphate buffer, $\mathrm{pH} 7.4,30 \%$ ethylene glycol, and $25 \%$ glycerol) at $-20^{\circ} \mathrm{C}$ until use.

\section{Human Tissue}

Deidentified, postmortem, fixed tissue specimens from medial frontal gyrus of $16 \mathrm{AD}$ patients and two healthy control subjects were obtained from the Brain Resource Center at Johns Hopkins University School of Medicine (Baltimore, MD). Five to six fixed tissue blocks each for samples previously identified as CERAD stages A, B, and C were recieved. ${ }^{26}$ On arrival, the tissues were cryoprotected in $50 \mathrm{~mL}$ of $30 \%$ sucrose at $4^{\circ} \mathrm{C}$ for 4 days. Each tissue block was divided into sections ( $35 \mu \mathrm{m}$ thick) using a freezing sliding microtome and stored in cryoprotectant solution at 
$-20^{\circ} \mathrm{C}$. A $1 / 12$ series of sections spaced at $420-\mu \mathrm{m}$ intervals were rinsed with tris-buffered saline (TBS) and deionized water. Sections were then mounted onto Superfrost Plus slides to dry for 4 nights at room temperature before staining. These studies were submitted for review at Baylor College of Medicine and deemed exempt from the requirement for institutional review board approval.

\section{Campbell-Switzer Silver Stain (Human and Mouse)}

This stain was performed, as described in US Patent Office, Histologic Analysis Method, patent US5192688 (1993). The detailed protocol for this stain is available from NeuroScience Associates (Knoxville, TN).

\section{Congo Red}

Slide-mounted sections of human cortex were rehydrated in running tap water for 20 to 30 minutes and stained with $0.25 \%$ Congo red (C6277; Sigma, St. Louis, MO) in $80 \%$ ethanol plus $1 \% \mathrm{NaOH}$ overnight. Excess dye was removed by rinsing with lukewarm tap water for 20 minutes before dehydration through ascending alcohols into xylene.

\section{Thioflavine-S Histology}

A $1 / 12$ series of mouse brain sections spaced at $420-\mu \mathrm{m}$ intervals were stained for thioflavine. Sagittal sections $(35 \mu \mathrm{m}$ thick) were rinsed, mounted onto Superfrost Plus slides (Thermo Fisher Scientific, Pittsburgh, PA), and dried overnight. Sections were rehydrated in running tap water, incubated for 10 to 15 minutes in $0.25 \%$ potassium permanganate, followed by 5 minutes in $1 \%$ potassium metabisulfite/ $1 \%$ oxalic acid, before staining in $0.02 \%$ thioflavine-S (T1892; Sigma) for 8 minutes. Staining was differentiated in $80 \%$ ethanol, followed by running tap water. Sections were dehydrated through xylene and coverslipped with Permount (Thermo Fisher Scientific).

\section{$A \beta$ Immunohistochemistry}

A 1/24 series of mouse brain sections was rinsed with TBS, pretreated with $88 \%$ formic acid for 1 minute at room temperature, and pretreated with $0.9 \% \mathrm{H}_{2} \mathrm{O}_{2}$ in $0.1 \%$ TBS with $0.3 \%$ Tween 20. The series was then blocked with TBS with Tween 20 containing 5\% normal goat serum before overnight incubation at $4{ }^{\circ} \mathrm{C}$ with rabbit anti-human $\mathrm{A} \beta$ antibody against a 30-amino acid fragment of the full-length peptide (71-5800; Zymed/Thermo Fisher Scientific, Waltham, MA), diluted 1:500 in blocking solution. (Note that the antigen for this antibody is also present in full-length APP; however, the formic acid incubation may serve to limit detection of full-length protein in tissue sections herein.) After several washes in TBS, sections were incubated with biotin-conjugated goat anti-rabbit secondary (Vectastain Elite ABC Kit, Rabbit IgG; Vector Laboratories, Burlingame, CA), diluted 1:500 in blocking solution for 1 hour at room temperature, followed by horseradish peroxidase-avidin conjugate diluted 1:50 in TBS for 30 minutes at room temperature. Sections were developed with diaminobenzidine (D4418; Sigma), then mounted, dehydrated, and coverslipped with Permount.

\section{Oligomer Immunofluorescence}

\section{Mouse Tissue}

A 1/12 series of sections was rinsed with TBS and blocked with TBS with $0.3 \%$ Tween 20 containing 5\% normal goat serum before overnight incubation at $4{ }^{\circ} \mathrm{C}$ with the following: i) purified rabbit anti-oligomer prefibrillar (OC) antibody [kind gift of Dr. Charles Glabe (University of California Irvine, Irvine, CA)], ii) mouse anti-A $\beta$ antibody 82E1 (10323; IBL, Hamburg, Germany), or iii) a mixture of the two antibodies. In all cases, primary antibodies were each diluted 1:1000 in blocking solution. After several washes in TBS, sections were incubated with Alexa-conjugated secondary antibodies: i) goat anti-rabbit IgG Alexa 568 (A11036; Molecular Probes/Life Technologies, Eugene, OR), ii) goat anti-mouse IgG Alexa 568 (A11004; Molecular Probes/Life Technologies), or iii) goat anti-rabbit IgG Alexa 647 and goat anti-mouse IgG Alexa 568 (A21245 and A11004, respectively; Molecular Probes/Life Technologies), diluted 1:500 in blocking solution for 1.5 hours at room temperature. Sections were washed with TBS before being counterstained with $0.002 \%$ thioflavine-S (T1892; Sigma), diluted in TBS for 8 minutes at room temperature. After two 1-minute washes in 50\% ethanol, followed by several washes in TBS, sections were mounted onto Superfrost Plus slides and coverslipped with Prolong Gold antifade reagent (Molecular Probes/Life Technologies).

\section{Human Tissue}

A 1/12 series of sections was rinsed with TBS and placed into Pyrex tanks (Corning, Corning, NY) containing preheated antigen retrieval buffer $(10 \mathrm{mmol} / \mathrm{L}$ sodium citrate and $0.05 \%$ Tween-20, $\mathrm{pH}$ 6.0). Immersed sections were incubated in boiling solution for 10 minutes and then cooled in place for 20 minutes at room temperature before rinsing with TBS buffer. Sections were then transferred into blocking solution containing 10\% normal goat serum before 48 hours of primary antibody incubation at $4^{\circ} \mathrm{C}$ with antiOC (1:1000). After washes in TBS, sections were incubated for 2 hours with secondary antibodies, diluted 1:500 in blocking solution (A11036; Molecular Probes/Life Technologies). Sections were washed with TBS, mounted onto Superfrost Plus slides, and coverslipped with Vectashield mounting medium (Vector Laboratories).

\section{Quantification of Amyloid Burden}

Sections stained for Campbell-Switzer silver, thioflavine-S, or $\mathrm{A} \beta$ were quantified using a custom macro written for AxioVision 4.8 (Carl Zeiss AG, Oberkochen, Germany). Color thresholds were used to distinguish deposits from background in high-resolution tiled scans of the entire stained section. After 
manually outlining the mouse cortex or hippocampus as the region of interest, the script was used to calculate the area occupied by positive pixels above threshold relative to the total area of interest in each image. Three to four (silver and thioflavine-S) sections spaced at $420-\mu \mathrm{m}$ intervals or two sections spaced at $840-\mu \mathrm{m}$ intervals (Zymed $A \beta$ ) were measured for each animal. Six tissue sections spaced at $420-\mu \mathrm{m}$ intervals were analyzed from each human tissue block; for each section, three nonoverlapping fields of view at $\times 10$ magnification $(1.42 \times 1.06 \mathrm{~mm})$ were captured for threshold analysis using the custom AxioVision macro (18 fields per tissue block).

\section{Biochemical Fractionation of Tissue Homogenates}

Frozen cortical samples were fractionated by a four-step extraction method similar to that previously described. ${ }^{27}$ Extraction began by mechanical dissociation in $250 \mu \mathrm{L}$ of $50 \mathrm{mmol} / \mathrm{L}$ tris- $\mathrm{HCl}, \mathrm{pH} 7.6,0.01 \% \mathrm{NP}-40,150 \mathrm{mmol} / \mathrm{L}$ $\mathrm{NaCl}, 2 \mathrm{mmol} / \mathrm{L}$ EDTA, $0.1 \% \mathrm{SDS}$, and $1 \times 1 \mathrm{mmol} / \mathrm{L}$ phenylmethylsulfonyl fluoride, $2 \mathrm{mmol} / \mathrm{L} \quad 1,10-$ phenanthroline monohydrate, and $1 \times$ protease inhibitor cocktail using five passes through a $1-\mathrm{mL}$ syringe with a $20-$ gauge needle. Proteins soluble in this extract were collected from the supernatant after 10 minutes at $800 \times g, 4^{\circ} \mathrm{C}$ (extract 1, low SDS, extracellular-enriched fraction). The remaining pellet was then mechanically dissociated by trituration with an Eppendorf micropipettor in $250 \mu \mathrm{L}$ of 50 $\mathrm{mmol} / \mathrm{L}$ tris- $\mathrm{HCl}, \mathrm{pH} 7.4,150 \mathrm{mmol} / \mathrm{L} \mathrm{NaCl}, 0.1 \%$ Triton $\mathrm{X}-100$, and $1 \times 1 \mathrm{mmol} / \mathrm{L}$ phenylmethylsulfonyl fluoride, 2 $\mathrm{mmol} / \mathrm{L} 1,10$-phenanthroline monohydrate, and $1 \times$ protease inhibitor cocktail. Proteins were collected from the supernatant of this extract after 90 minutes at $16,100 \times \mathrm{g}, 4^{\circ} \mathrm{C}$ (extract 2, low Triton X-100, cytosol-enriched fraction). The remaining pellet was then triturated with a micropipettor, followed by passive lysis on a rotating platform for 15 minutes at $4^{\circ} \mathrm{C}$ in $250 \mu \mathrm{L}$ of $50 \mathrm{mmol} / \mathrm{L}$ tris- $\mathrm{HCl}, \mathrm{pH} 7.4$, $150 \mathrm{mmol} / \mathrm{L} \mathrm{NaCl}, 0.5 \%$ Triton X-100, $1 \mathrm{mmol} / \mathrm{L}$ EGTA, $3 \%$ SDS, $1 \%$ deoxycholate, and $1 \times 1 \mathrm{mmol} / \mathrm{L}$ phenylmethylsulfonyl fluoride, $2 \mathrm{mmol} / \mathrm{L}$ 1,10-phenanthroline monohydrate, and $1 \times$ protease inhibitor cocktail. Proteins were collected from the supernatant of this extract after 90 minutes at $16,100 \times g, 4^{\circ} \mathrm{C}$. Proteins were collected from this supernatant after a final clarification spin of 60 minutes at $100,000 \times g$ (extract 3, high SDS, membrane-enriched fraction). Each fraction was depleted of endogenous immunoglobulins by sequential incubation for 1 hour at $4^{\circ} \mathrm{C}$ with $50 \mu \mathrm{L}$ of Protein A-Sepharose, Fast Flow, followed by $50 \mu \mathrm{L}$ of Protein G-Sepharose, Fast Flow (GE Healthcare Life Sciences, Pittsburgh, PA). All extracts were clarified by 90 minutes at $16,100 \times g, 4^{\circ} \mathrm{C}$, before use.

\section{Immunoprecipitation}

Protein extract $(200 \mu \mathrm{g})$ was diluted to $1 \mathrm{~mL}$ with dilution buffer $(50 \mathrm{mmol} / \mathrm{L}$ tris- $\mathrm{HCl}, \mathrm{pH} 7.4$, and $150 \mathrm{mmol} / \mathrm{L} \mathrm{NaCl})$ and incubated with $5 \mu \mathrm{g}$ of $6 \mathrm{E} 10$ overnight at $4{ }^{\circ} \mathrm{C}$. The following day, $50 \mu \mathrm{L}$ of Protein $\mathrm{G}-$ Sepharose, Fast Flow (GE Healthcare Life Sciences), was added, washed 1:1 (v:v) with immunoprecipitation buffer A $(50 \mathrm{mmol} / \mathrm{L}$ tris- $\mathrm{HCl}$, $\mathrm{pH} 7.4,300 \mathrm{mmol} / \mathrm{L} \mathrm{NaCl}, 0.1 \%$ Triton X-100, and $1 \mathrm{mmol} /$ L EDTA), incubated at $4{ }^{\circ} \mathrm{C}$ for 20 minutes, aspirated, then washed with immunoprecipitation buffer $\mathrm{B}(50 \mathrm{mmol} / \mathrm{L}$ tris- $\mathrm{HCl}, \mathrm{pH} 7.4,150 \mathrm{mmol} / \mathrm{L} \mathrm{NaCl}, 0.1 \%$ Triton $\mathrm{X}-100$, and $1 \mathrm{mmol} / \mathrm{L}$ EDTA), ${ }^{27}$ and incubated at $4{ }^{\circ} \mathrm{C}$ for 20 minutes. The beads were washed twice in $1 \mathrm{~mL}$ of dilution buffer, and proteins were eluted by boiling in $30 \mu \mathrm{L}$ of SDSPAGE loading buffer containing 5\% $\beta$-mercaptoethanol.

\section{Immunoblotting}

Protein $(100 \mu \mathrm{g})$ per sample was diluted with SDS-tricine loading buffer containing 5\% $\beta$-mercaptoethanol, denatured at $95^{\circ} \mathrm{C}$ for 5 minutes, and electrophoresed onto $10 \%$ to $20 \%$ SDS-polyacrylamide tris-tricine gels (Bio-Rad Laboratories, Hercules, CA). Proteins were transferred to nitrocellulose, and membranes were boiled in phosphate-buffered saline for 5 minutes. Membranes were blocked in tris-buffered saline containing $0.1 \%$ Tween 20 , containing $5 \%$ bovine serum albumin (A3803; >98\% grade; Sigma) for 2 hours at room temperature, and probed with either 6E10 (SIG-39320; Covance, Princeton, NJ) or biotinylated-6E10 (SIG-39340; Covance), diluted 1:2500 in blocking solution. Primary antibodies were detected using anti-IgG conjugated with either biotin or infrared dyes (LI-COR Biotechnology, Lincoln, NE). When biotin-conjugated antibodies were used, DyLight800conjugated Neutravidin (22853; Thermo Fisher Scientific) was added to amplify the signal. Blots were imaged with an Odyssey detection system (LI-COR). Densitometry analyses were performed using OptiQuant software (Packard BioScience/ PerkinElmer, Meriden, CT) or Image Studio software (LICOR).

\section{Dot Blotting}

Cortical extracts 1 and $3(2 \mu \mathrm{g}$; low and high SDS, respectively) were mixed with sterile filtered deionized water in a total volume of $2.5 \mu \mathrm{L}$. Each sample was then adsorbed onto a nitrocellulose membrane until dry. After a brief activation in 10\% methanol/TBS, the membrane was boiled in phosphate-buffered saline to enhance antigen detection, as previously described. ${ }^{27}$ Membranes were blocked in TBS containing 5\% bovine serum albumin for 60 minutes, then moved to primary antibody: $6 \mathrm{E} 10,4 \mathrm{G} 8$, and $1 \mathrm{G6}(1: 2500 ; 803003,800703$, and 806001, respectively; BioLegend, San Diego, CA), nonfibrillar A $\beta$ oligomers (A11) and OC (1:2000; kind gifts from Rakez Kayed, University of Texas Medical Branch, Galveston, TX), or actin (1:10,000; MAB1501; MilliporeSigma/EMD Millipore, Billerica, MA) for overnight incubation at $4^{\circ} \mathrm{C}$. After several washes, anti-mouse $\operatorname{IgG} \operatorname{IR}_{800}(1: 100,000)$ and antirabbit $\operatorname{IgG} \mathrm{IR}_{680}$ secondary antibodies $(1: 150,000)$ were 
Table 1 Cohort Demographics

\begin{tabular}{lllll}
\hline & CERAD stage & & \\
\cline { 2 - 4 } Variable & $\mathrm{A}$ & $\mathrm{B}$ & 6 & C \\
\hline Specimens, $n$ & 5 & 5 & 6 & Healthy controls \\
Median age, years (range) & $88(84-90)$ & $86(68-92)$ & $78.5(61-88)$ & NA (56-79) \\
MMSE score, median (range) & $30(\mathrm{NA})$ & $20(12-24)$ & $11.5(7-14)$ & NA \\
Female sex, \% & 80 & 80 & 66 & 50 \\
Braak stage, median (range) & $3(3-4)$ & $4(2-6)$ & $6(6)$ & NA (1-2) \\
Postmortem delay in hours, median (range) & $12(5-22)$ & $19(13-38.5)$ & $10(3.5-23)$ & NA (5-7) \\
\hline
\end{tabular}

Note that MMSE scores were only available for a subset of patients: $n=1$ for CERAD stage $A ; n=3$ for CERAD stage $B$ (two of the three were last evaluated 5 years before death); $n=4$ for CERAD stage $C$; and $n=0$ for controls. Detailed characteristics for individual subjects are provided in Supplemental Table S1. CERAD, Consortium to Establish a Registry for Alzheimer Disease; MMSE, Mini-Mental State Examination; NA, not applicable.

used for detection with a LI-COR Odyssey imager. All steps were performed without detergent to enhance A11/OC binding of oligomeric species, as previously reported. ${ }^{28}$

\section{Oligomeric $A \beta$ ELISA}

Human $A \beta$ oligomers were detected by a solid-phase sandwich enzyme-linked immunosorbent assay (ELISA) kit (27725; IBL America, Minneapolis, MN), with a sensitivity range of 18.98 to $1215 \mathrm{pmol} / \mathrm{L}$. On the basis of pilot studies, the low-SDS extracellular-enriched cortical extracts were diluted with the manufacturer's enzyme immunoassay buffer at a ratio of 1:1 for 3- and 6-month samples, 1:4 for 9month samples, and 1:9 for 12-month samples. Duplicate $100-\mu \mathrm{L}$ aliquots of each sample were incubated with $20 \mu \mathrm{L}$ of horseradish peroxidase-conjugated 82E1 antibody for 1 hour at $4{ }^{\circ} \mathrm{C}$. This mixture $(100 \mu \mathrm{L})$ was added to a 96-well plate precoated with $82 \mathrm{E} 1$ and incubated for 1 hour at $4^{\circ} \mathrm{C}$. After three washes with buffer, $100 \mu \mathrm{L}$ of chromagen (tetramethylpenzidine) was added to each well and incubated for 30 minutes at room temperature in the dark. Reactions were stopped by addition of $100 \mu \mathrm{L}$ of stop solution, and absorbance was read at $450 \mathrm{~nm}$.

\section{Statistical Analysis}

Data were analyzed using one- or two-way analysis of variance or $t$-test, where appropriate. All post hoc comparisons were conducted using Tukey post hoc tests. Search strategy data were analyzed using $\chi^{2}$ tests. Statistical analyses and graphs were generated using Prism 6.0 (GraphPad Software, La Jolla, CA). Graphs display group means \pm SEM.

\section{Results}

Plaque Load in APP/TTA Mice Parallels CERAD Stages of Human $A D$ until the Final Age Tested

The APP/TTA transgenic model was chosen for these studies because it develops early-onset $A \beta$ pathology that progresses rapidly with age. ${ }^{23}$ The model thus provided a good system in which to evaluate the relationship between plaque load, oligomeric $A \beta$, and cognitive function over a broad range of pathologic severity. To better frame the studies within the context of the human disease, the severity of plaque load was staged in the APP/TTA model against that of human tissue samples. Human medial prefrontal cortex samples were preselected to span CERAD stages A to $\mathrm{C}$ (Table 1 and Supplemental Table S1) for comparison against APP/TTA mice harvested after 3, 6, 9, or 12 months of transgenic APP overexpression. Both sets of tissue were stained for argyrophilic pathology using the CampbellSwitzer silver stain, which provides excellent signal/noise ratio, with particular sensitivity for diffuse plaques.

Sparse protein deposits were present in the APP/TTA mice by 3 months of APP onset and increased progressively with time (Figure 1, A and B, and Supplemental Figure S1). Cortical plaque density at 3 months was similar to that of CERAD A cases $(<5 \%$ surface area), at 6 months to CERAD B cases (20\% to $25 \%$ surface area), and at 9 months to CERAD C cases (40\% to $60 \%$ surface area) (Figure 1, A and B). By 12 months of APP overexpression, mice reached a degree of pathology that would be exceptional in human $\mathrm{AD}$, with an average $81 \%$ cortical surface area (66\% in hippocampus) stained by Campbell-Switzer silver. The 3-, 6-, and 9-month mice thus nicely represented the range of pathology normally observed across the three human CERAD stages, whereas the 12-month animals would test the physiological limit between $A \beta$ accumulation and cognitive decline. Although the Campbell-Switzer stain has excellent signal/noise characteristics for quantitative analysis, its high sensitivity also makes it challenging to compare with more traditional methods for amyloid detection. Therefore, the APP/TTA mice were evaluated for total plaque burden by anti-A $\beta$ immunostaining and for fibrillar amyloid by thioflavine-S histology. Values obtained from these analyses are considerably more conservative, with a range of $3 \%$ to $14 \%$ average $A \beta^{+}$cortical area between 3 and 12 months, and just $0.14 \%$ to $2.1 \%$ thioflavine- $\mathrm{S}^{+}$area over the same period (Figure 1, C and D, and Supplemental Figure S1). Thioflavine-S staining of the human tissue was hindered by low signal and high background in the fixed frozen sections; instead, Congo red histochemistry was used 
A Campbell-Switzer silver
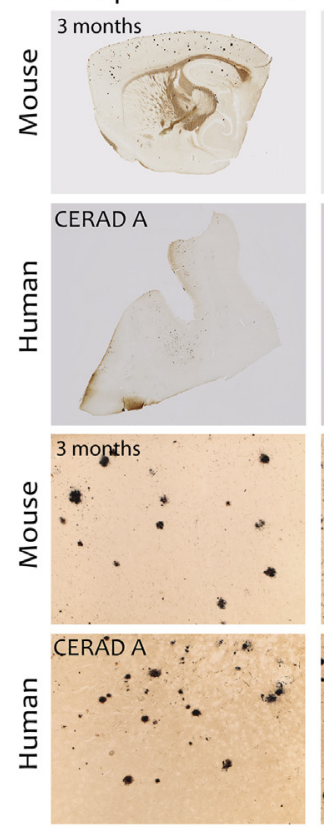

C

Thioflavine-S / Congo Red
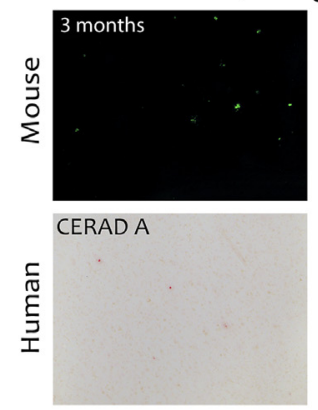
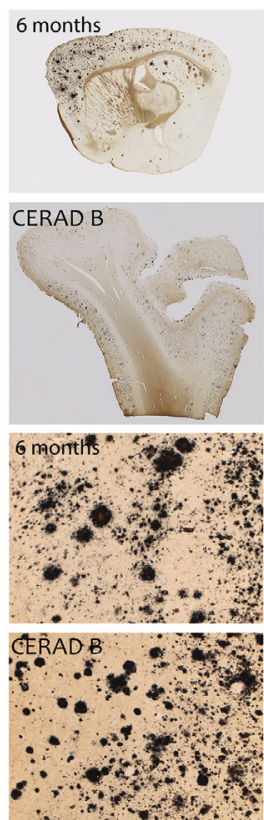

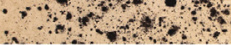
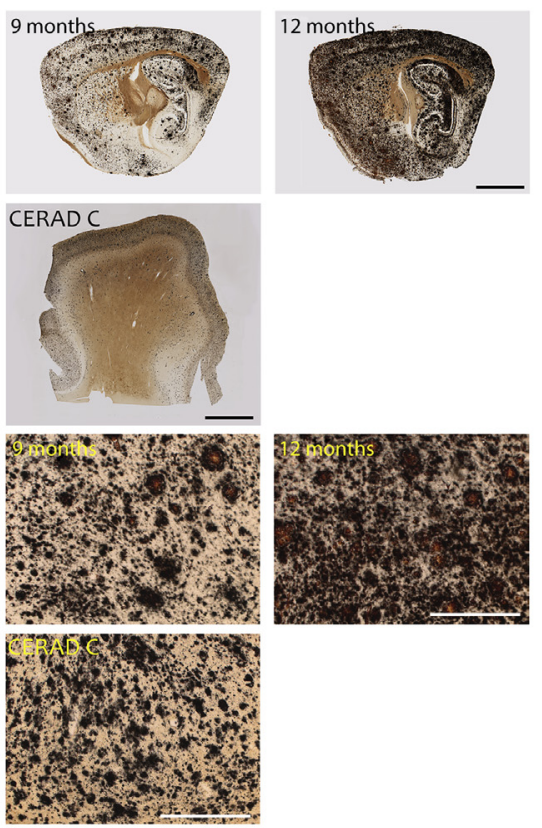

B

Campbell-Switzer silver (\% surface area)

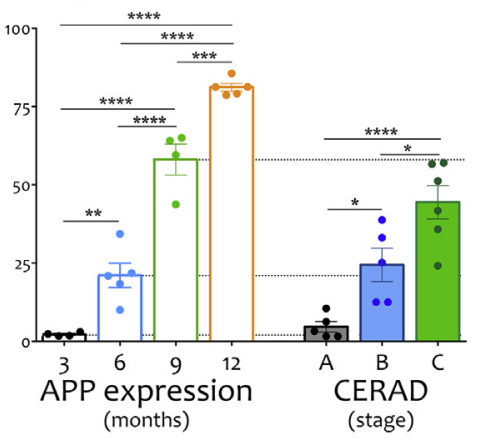

Thioflavine-S (\% surface area)

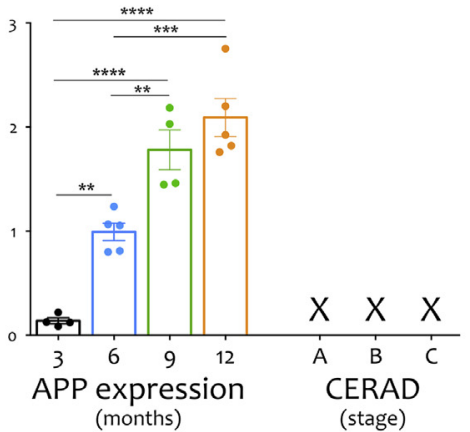

Figure 1 Plaque burden in APP/TTA mice parallels human Consortium to Establish a Registry for Alzheimer Disease (CERAD) staging until late ages. A: Campbell-Switzer silver stain was used to visualize argyrophilic protein aggregates in tissue sections from APP/TTA mice and human medial frontal cortex. Top rows: Tissue sections at low magnification. Bottom rows: Higher magnification of the cortical mantle oriented with the pial surface at the top. Duration of transgenic APP expression is indicated for mouse tissue, and CERAD stage is indicated for human tissue. B: Total cortical surface area stained by Campbell-Switzer silver was quantified by digital analysis for both mouse (left side) and human (right side) tissues. One-way analysis of variance: mouse, $F(3,14)=127.7$, $P<0.0001$; human, $F(2,13)=19.16, P=0.0001$. Dotted lines highlight comparison between amyloid area measured after 3, 6, or 9 months of transgenic APP expression in mice and CERAD stage A, B, or C pathology in patient tissue samples. C: Thioflavine-S staining was used to visualize fibrillar plaques in mouse tissue, whereas Congo red histology was used to reveal comparable deposits in human tissue. Fields for both stains were taken from the cortical mantle, as shown for A. D: Total cortical surface area stained by thioflavine-S was quantified for mouse tissue [one-way analysis of variance, $F(3,14)=52.00, P<0.0001$ ]. Graphs indicate significant post hoc comparisons. ${ }^{*} P<0.05,{ }^{*} P<0.01,{ }^{* * *} P<0.001$, and ${ }^{* * *} P<0.0001$. Scale bars: $2 \mathrm{~mm}(\mathbf{A}$, top rows); $500 \mu \mathrm{m}(\mathbf{A}$, bottom rows, and $\mathrm{C}$ ). $\mathrm{X}$, the signal from Congo red was not strong enough to permit digital analysis of human fibrillar plaque load.

to label fibrillar deposits in these samples. The distribution and density of thioflavine ${ }^{+}$plaques in mouse cortex between 3 and 9 months was qualitatively similar to that of Congo $\mathrm{red}^{+}$deposits in the human samples, although the latter were too pale to accurately quantify by digital imaging (Figure 1C). The quantitative and qualitative comparison between human cortical samples and these APP transgenic mice provided a framework for subsequent behavioral and biochemical studies with this model.

\section{APP/TTA Mice Display Progressive Decline in Spatial Learning with Age}

Behavioral testing used a cross-sectional design in which a naive set of mice was examined at each age. Transgene expression was initiated in young adult animals at 6 weeks of age and continued for 3, 6, 9, and 12 months before behavioral characterization. All four genotypes generated by the intercross of CaMKII $\alpha$-TTA $\times$ tetO-APPswe/ind were tested: nontransgenic, APP, TTA, and APP/TTA, with 8 to 
12 animals per genotype at each age, including both sexes. Of these animals, only bigenic APP/TTA mice carrying both the TTA and the TTA-responsive APP transgene produced pathogenic APP and formed amyloid deposits. APP singletransgenic mice carried the transgene but lacked the TTA transactivator required for its expression. Conversely, TTA single-transgenic mice expressed the transactivator but lacked the TTA-responsive APP transgene. Before testing, all mice underwent open field assessment to rule out locomotor deficits and straight swim training to confirm each animal could perform this basic function required for subsequent cognitive testing (Supplemental Figure S2).

Spatial learning and reference memory were tested using a modified version of the MWM in which mice are trained to prespecified performance criteria before being tested for long-term memory. ${ }^{24}$ Specifically, animals undergo daily training sessions of four trials per day to locate a hidden escape platform in a fixed location. At the end of each day, animals undergo an immediate probe trial with the platform removed to assess short-term memory for the trained location. Performance during this immediate probe trial is evaluated against preset criteria for this task, with successful performance defined as $\geq 35 \%$ of the swim path in the correct quadrant and at least $40 \%$ of total platform crossings over the correct site compared with other possible platform locations. Mice were trained for a maximum of 8 (3- and 6month cohorts) or 10 (9- and 12-month cohorts) days; however, once a mouse reached criteria performance, the mouse was retired from further training and given its final probe trial testing long-term memory the following day. This procedure yields several measures of cognitive performance from a single assay and can be used with mice spanning a wide range of abilities. Most important, by bringing all animals to the same performance level before testing long-term recall, this approach disentangles learning from memory.

Consistent with past studies of cognitive function in wildtype animals, ${ }^{29-32}$ age had virtually no effect on MWM learning in control mice over the range tested. There were no significant differences in path length to the hidden platform during training or in the average number of days to reach criteria performance between nontransgenic, APP, and TTA mice at any age (Figure 2).

In contrast to the relative preservation of spatial learning in control animals, MWM acquisition in the APP/TTA mice declined significantly with the duration of APP overexpression (Figure 2 and Supplemental Table S2). After 3 months, APP/TTA took a less direct route to the hidden platform than nontransgenic controls on the first 2 days of training (Figure 2A). By 6 months, APP/TTA mice swam farther than controls to reach the platform every day that comparisons could be made. The deficit in spatial acquisition became more pronounced by 9 and 12 months. By 12 months of APP overexpression, APP/TTA mice showed no change in path length across the full 10 days of training.
Accompanying the decline in spatial acquisition, a parallel decrease in STM performance with longer APP overexpression was also noted. STM was assessed by proximity to the trained platform location during probe trials conducted immediately after each training session. At 3 months, APP/TTA mice were impaired on their first STM trial, but by the second day of testing, they performed as well as controls (Figure 2B). At this age, the rate at which APP/ TTA mice reached criteria performance was not significantly different from controls (Figure 2C).

At 6 months, APP/TTA mice were significantly less accurate than all three control groups during the first two STM trials, but by the third day of testing, they had caught up with all but the nontransgenic group (Figure 2B). This age is the first at which APP/TTA mice required significantly more days of training than controls to learn the maze. At 9 and 12 months, proximity to the platform during STM trials was impaired every day on which genotype comparisons could be made and was significantly different from all three control groups. At 9 months, STM performance by APP/ TTA mice was so poor that they required twice the number of training days to reach criteria performance as controls, and by 12 months, $50 \%$ of APP/TTA mice failed to reach criteria at all within the allotted 10 days of training (Figure 2C).

The main rationale for using a train-to-criteria design is that it allows any deficits in long-term memory to be distinguished from problems in learning. Herein, long-term memory tested 24 hours after reaching criteria performance was unexpectedly found to be completely normal in APP/ TTA mice at all ages tested (Figure 2D). Bear in mind that this comparison includes only mice that reached criteria performance during training and, therefore, excludes 3 of 11 APP/TTA mice at 9 months and 5 of 9 animals at 12 months.

The progressive impairment of spatial learning with increasing duration APP overexpression is most clearly illustrated by re-plotting MWM data for APP/TTA mice to directly compare performance across age (Figure 3). Here, data shown in Figure 2 are plotted together in a single graph to highlight the temporal evolution in three measures of MWW performance: average pathlength to the hidden platform (Figure 3A), percentage of animals reaching criteria performance for each training day (Figure 3B), and average number of training days required to reach criteria performance across age (Figure 3C). This latter comparison provides the clearest snapshot of cognitive decline with age and amyloid burden in APP/TTA mice in contrast to the relative stability in spatial learning across age in TTA controls.

\section{Primary Navigation Strategy Shifts with Age from Directed to Random in Amyloid-Bearing Mice}

A rough measure of cognitive flexibility can be gleaned from looking at the way in which mice solve the MWM 
A
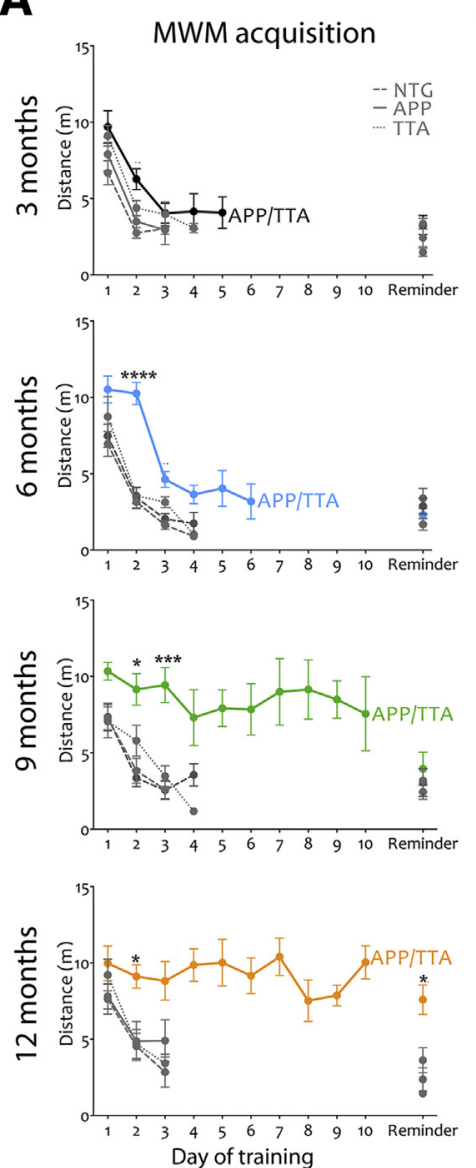

B
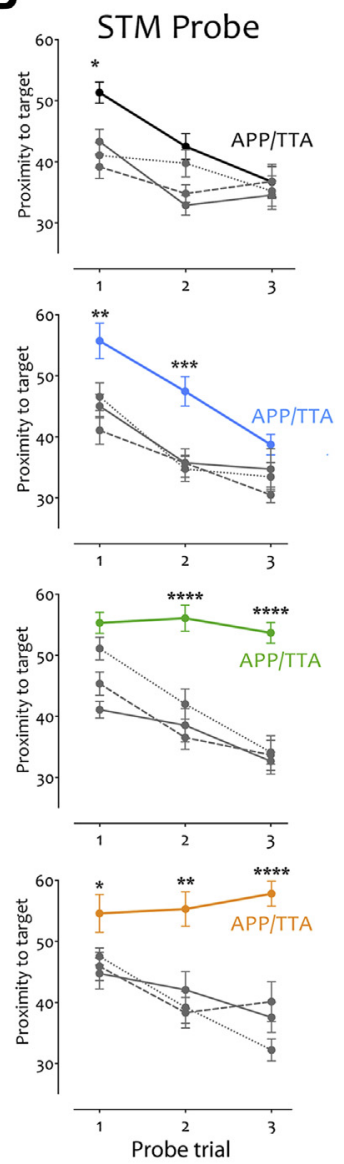

C
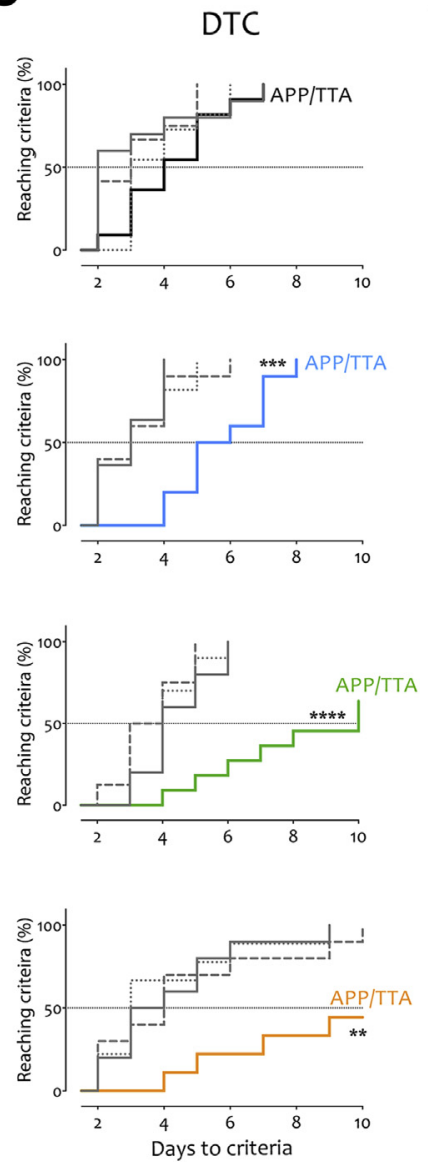

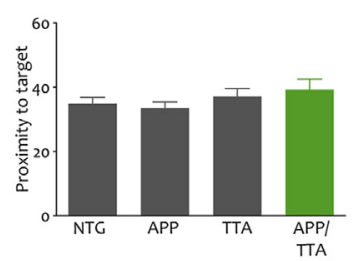

LTM
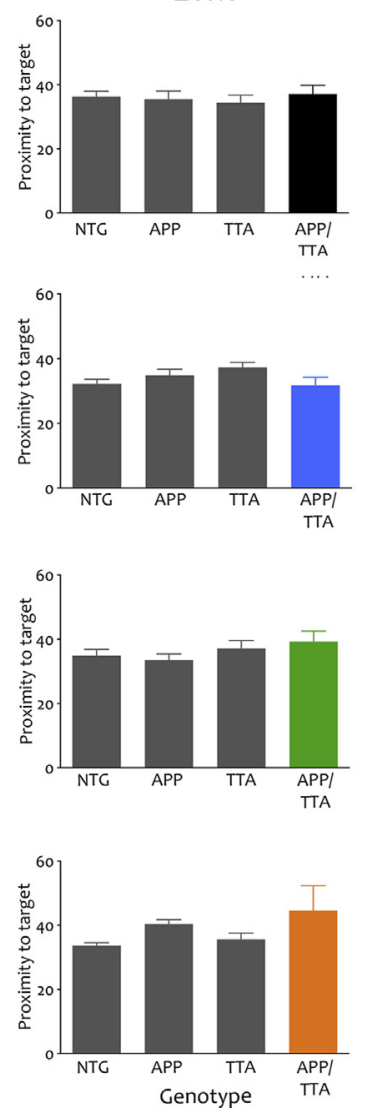

Figure 2 Morris water maze (MWM) reveals substantial decline in spatial learning with increasing plaque load. A: Acquisition of spatial information, measured as the average distance traveled to reach the hidden platform during each training session, is mildly impaired in APP/TTA mice after 3 months of transgene expression, but by 9 and 12 months, it reaches a state at which no improvements in performance were achieved over 10 days of training [two-way repeated measures (RM) analysis of variance, main effect of genotype, 3 months: $F(3,38)=7.20, P<0.001 ; 6$ months: $F(3,38)=26.21, P<0.0001 ; 9$ months: $F(3,34)=26.73, P<0.0001 ; 12$ months: $F(3,35)=5.52, P<0.01]$. Asterisks indicate significant post hoc comparisons for APP/TTA only when consistent across all three control groups (see Supplemental Table S2 for complete post hoc results). B: At 3 and 6 months, APP/TTA mice swim farther from the trained escape location during short-term memory (STM) tests at the end of each day, but catch up to control performance by the second (3 months) or third ( 6 months) day of testing. In contrast, short-term memory impairments persist across the first 3 days of testing at 9 and 12 months [two-way RM analysis of variance, main effect of genotype, 3 months: $\mathrm{F}(3,38)=5.06, P<0.01 ; 6$ months: $\mathrm{F}(3,38)=13.09, P<0.0001 ; 9$ months: $\mathrm{F}(3,34)=34.62, P<0.0001$; 12 months: $\mathrm{F}(3,34)=17.06, P<0.0001$ ] (see Supplemental Table S2 for complete post hoc results). C: Percentage of each genotype reaching criteria performance on each day of training. The average number of training days to reach criteria performance (DTC) was similar for all genotypes at 3 months, but by 6 months the rate of APP/TTA success was significantly delayed compared to controls (Chi-square, 3 months: $X 2=3.41, \mathrm{df}=3, P>0.05 ; 6$ months: $X 2=$ $19.04, \mathrm{df}=3, P<0.001 ; 9$ months: $X 2=23.97, \mathrm{df}=3, P<0.0001 ; 12$ months: $X 2=14.66, \mathrm{df}=3, P<0.01)$. Intersection with dashed line indicates the number of training days required for $50 \%$ of each genotype to reach criteria performance. D: Despite any differences in acquisition and short-term memory, all APP/TTA mice that reached criteria performance remember the trained escape location as well as controls during long-term memory (LTM) testing [two-way analysis of variance, main effect of genotype: $\mathrm{F}(3,136)=1.70, P>0.05]$. Graphs indicate significant post hoc comparisons. Colored symbols/lines indicate APP/TTA groups; other genotypes are shown in gray. Solid lines for APP, dotted lines for TTA, and dashed lines for nontransgenic. ${ }^{*} P<0.05,{ }^{*} P<0.01$, $* * * P<0.001$, and ${ }^{* * * * P}<0.0001$.

during successive days of training. Search strategy normally evolves over time from the systematic (nonspatial) solutions used during initial trials to more direct and flexible spatial approaches. Search patterns in APP/TTA mice and TTA controls were categorized to determine whether and how the search strategies used by APP/TTA mice changed with increasing plaque load. Search patterns were broadly classified into three categories: i) repetitive looping, frequently used by mice that did not find the platform within the allotted time; ii) systematic nonspatial, indicative of mice that searched for the platform but struggled to find it; and iii) spatial, used by mice that learned the trained location and swam directly to it (Figure $4 \mathrm{~A}^{25}$ ). As expected, TTA controls at all ages showed a consistent evolution of search strategy over successive days of training. On the first day of training, mice either randomly explored the maze or performed thigmotaxic looping. By the second day, TTA animals began to increasingly use spatial strategies, and by the third day, spatial searching was the primary strategy used in all age groups (Figure 4B). 


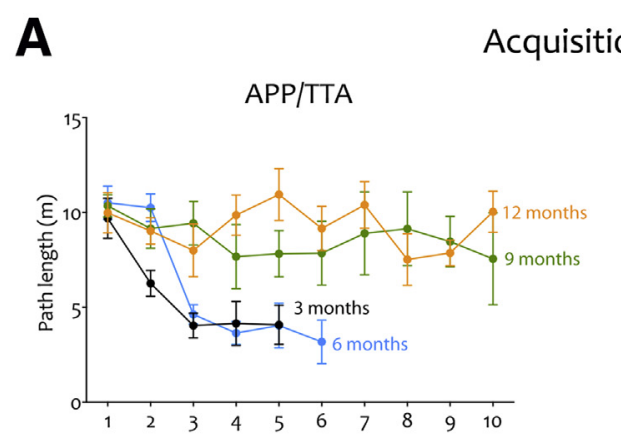

B

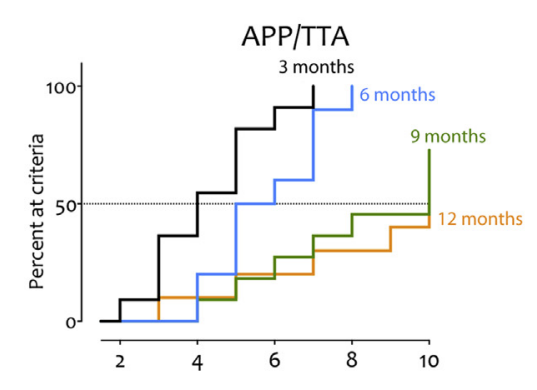

C

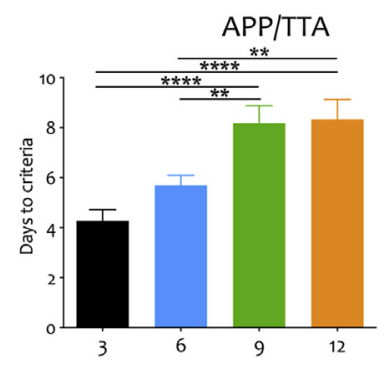

DTC

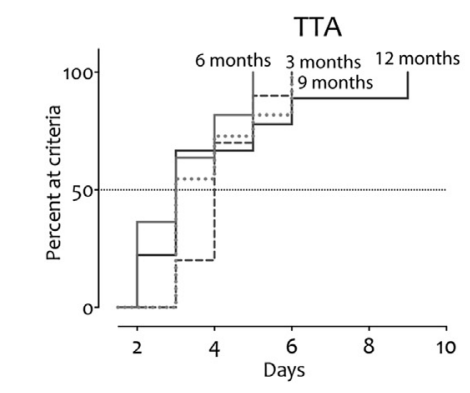

\section{Mean DTC}
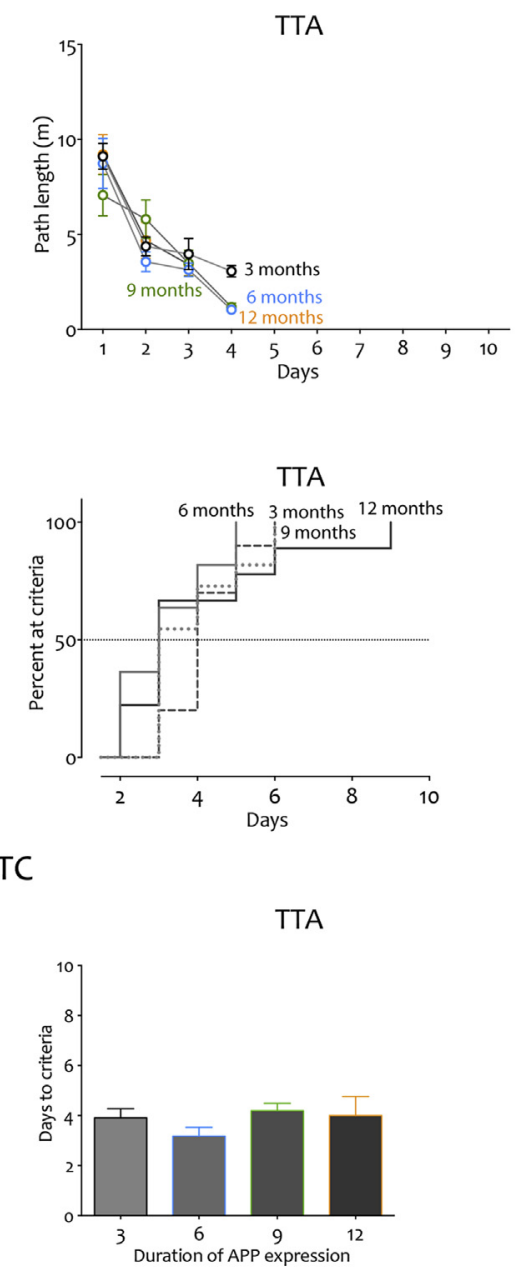

Figure 3 Comparison of performance across age highlights the progressive decline in APP/TTA mice. These graphs replot by genotype Morris water maze (MWM) data shown by age in Figure 2 to illustrate the impact of transgene expression over time in APP/TTA mice. In contrast, no agerelated differences are found for any measure of performance in TTA controls. A: Path length during MWM training (two-way RM ANOVA, age $\times$ day interaction, APP/TTA: $F(12,144)=4.112, P<$ 0.0001; TTA: $F(3,37)=2.793, P=0.0538$; see Supplemental Table S3 for complete post hoc results). B: Percentage of total reaching criteria each day. Intersection with dashed line indicates the number of training days required for $50 \%$ of each age group to reach criteria performance (Chisquare, APP/TTA: $X 2=26.34, \mathrm{df}=3, P<$ 0.0001 ; TTA: $X 2=3.35, \mathrm{df}=3, \mathrm{P}>0.05)$. C: Average days of training to reach criteria performance [DTC; two-way analysis of variance, age $\times$ genotype interaction: $F(3,147)=2.46$, $P<0.01$ ]. All three measures of spatial learning and short-term memory are significantly worse at 9 and 12 months than at 3 or 6 months. ${ }^{*} P<0.05$, $* * P<0.01$, and $* * * * P<0.0001$.
At young ages (3 and 6 months), search strategy in APP/ TTA mice evolved from nonspatial to spatial in much the same way as in TTA controls, albeit over more days of training. On day 3, the last day for which most TTA mice were still in training, there was no significant difference in the use of spatial strategies between APP/TTA mice and controls at either 3 or 6 months (Figure 4B). However, after longer periods of transgenic APP expression, APP/TTA mice began to use spatial strategies significantly less than controls. By 12 months, APP/TTA animals used spatial strategies significantly less than at 3 or 6 months (3 versus 12 months: $X^{2}=9.70, \mathrm{Df}=2, P<0.01 ; 6$ versus 12 months: $\left.X^{2}=14.39, \mathrm{Df}=2, P<0.001\right)$. This inability to engage spatial strategies likely contributed to their ultimate failure in learning the trained location.

\section{Increasing Levels of Oligomeric $A \beta$ Attend the Decline} in Spatial Learning

Once behavioral testing was complete, forebrain tissue was collected from the APP/TTA mice to identify what forms of oligomeric $\mathrm{A} \beta$ accumulated over time and might support the observed decline in spatial learning as pathology worsened. $\mathrm{A} \beta$ species was first assessed by size using immunoprecipitation and Western blotting. Cortical extracts from three to four behaviorally tested APP/TTA mice at each age were prepared to isolate proteins soluble in low-SDS solution (0.1\% SDS, enriched but not exclusive for extracellular proteins) and proteins soluble in high-SDS solution (3\% SDS, enriched but not exclusive for membrane-associated proteins). The low-SDS fraction contained sufficient 6E10reactive protein to examine directly by Western blot (Figure 5A). The high-SDS fraction was examined after immunoprecipitation with $4 \mathrm{G} 8$ to concentrate $\mathrm{APP}$ and $\mathrm{A} \beta$ species (Figure 5A). All extracts were run on denaturing SDS gels and, therefore, reflect only $A \beta$ species that are SDS stable. Nevertheless, this approach provides a qualitative appreciation of changes in the relative structure and solubility of $A \beta$ species that accumulate in the brain as cognitive performance declines.

Immunoblotting detected multiple $A \beta$ species in the lowand high-SDS extracts, including monomer, dimer, and 


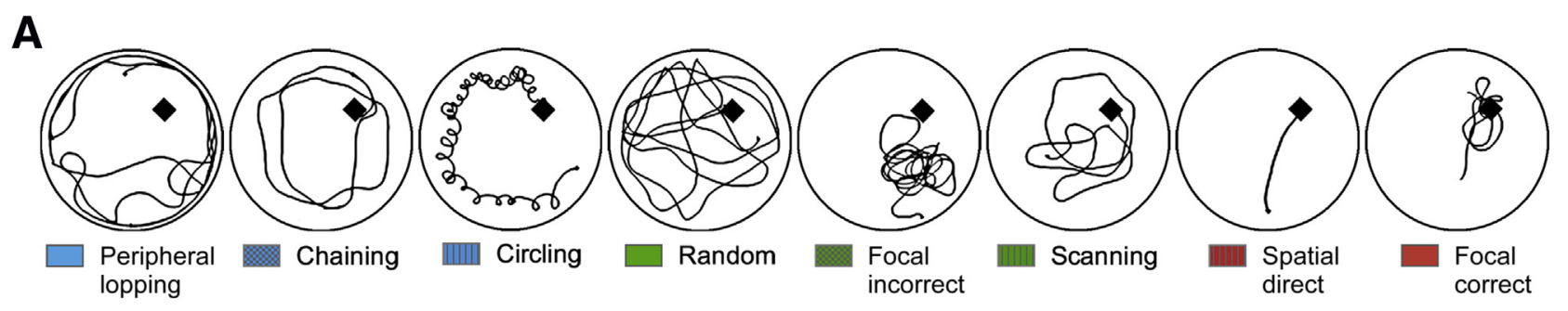

B

3 months
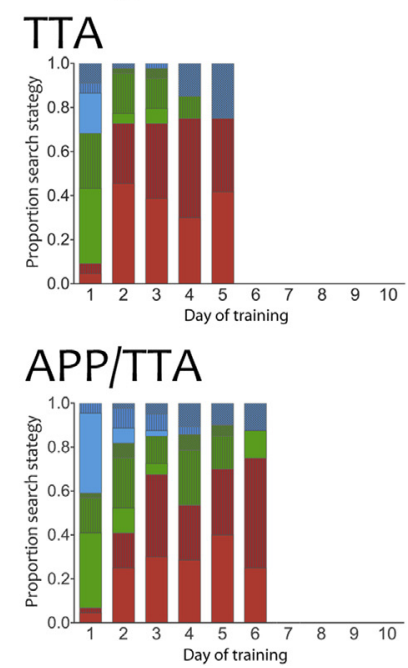

6 months
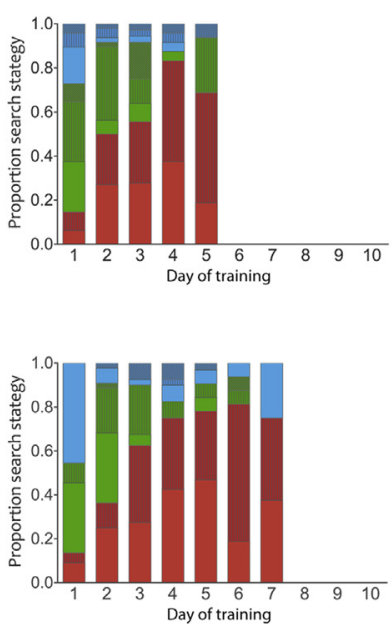

9 months
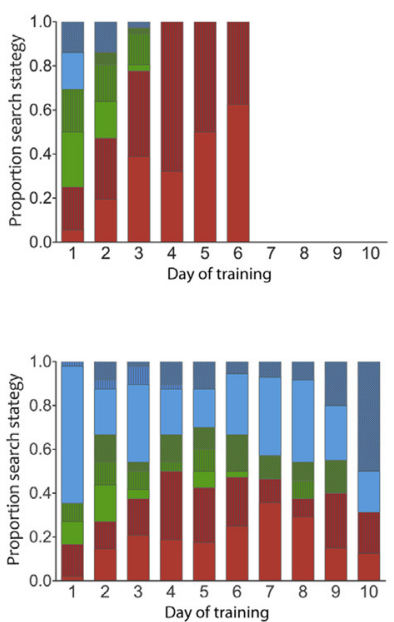

12 months
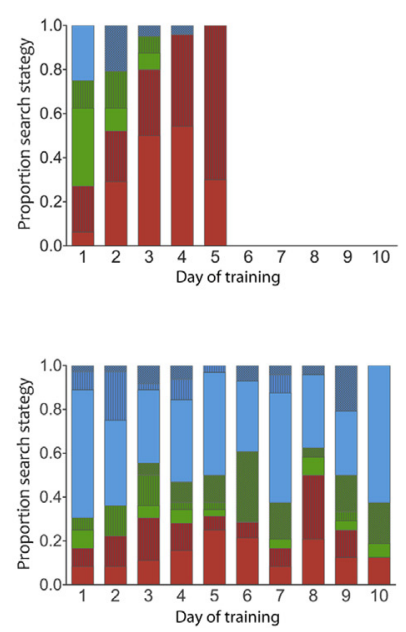

Figure 4 APP/TTA mice fail to engage spatial search strategies in Morris water maze at advanced ages. A: Diagrams illustrate the classifiers used to identify search strategy on the basis of swim path during hidden platform training. Eight distinct search patterns are divided into three main strategies: repetitive looping (blue), systematic nonspatial (green), and spatial (red). ${ }^{25}$ B: Strategy use by TTA and APP/TTA mice is graphed as a proportion of total daily trials using the color scheme illustrated in A. Search strategy is shown for all days on which two or more mice were still in training. For control animals, age has no effect on the rate at which mice engage a spatial search strategy (TTA, day 3 strategy versus age: $\left.\chi^{2}, \chi^{2}=7.73, \mathrm{DF}=6, P>0.05\right)$. In contrast, APP/TTA mice became less able to adopt spatial strategies with prolonged transgene expression (APP/TTA day 3 strategy versus age: $\chi^{2}, X^{2}=24.90, \mathrm{Df}=6, P<0.001$ ), and their use of different strategies becomes increasingly divergent from TTA controls (day 3 strategy APP $/$ TTA versus TTA: 3 months: $X^{2}=4.70$, Df $=2$, $P>0.05 ; 6$ months: $X^{2}=0.65, \mathrm{Df}=2, P>0.05 ; 9$ months: $X^{2}=20.11, \mathrm{Df}=2, P<0.001 ; 12$ months: $\left.X^{2}=21.59, \mathrm{Df}=2, P<0.001\right)$.

$\mathrm{A} \beta * 56$, along with $\mathrm{APP}-\mathrm{C}$-terminal fragment and fulllength APP. Both fractions contained $A \beta$ monomer and $\mathrm{A} \beta * 56$; however, soluble APP ectodomain was identified in the low-SDS extract, consistent with extracellular localization (Figure 5A), and full-length APP was identified in the high-SDS extract, consistent with membrane localization (Figure 5B). Dimeric A $\beta$ was detected only after 4G8 immunoprecipitation, followed by 4G8 immunoblot; no signal at this size was seen on $6 \mathrm{E} 10$ immunoblots. This distinction may be because of either preferential epitope presentation in dimeric conformation ${ }^{33}$ or the accumulation of mouse $A \beta$ with increasing levels of human peptide. Quantitation of the species immunoprecipitated from the membrane-enriched high-SDS extract confirmed that fulllength APP expression did not change over time, whereas $A \beta$ monomer, dimer, and $A \beta * 56$ increased substantially (Figure 5B). Dimers increased disproportionately to monomeric $A \beta$, increasing nearly 500 -fold between 3 and 12 months of transgenic APP expression, whereas monomers increased just 45 -fold. $A \beta * 56$ levels also increased disproportionately to monomer, but in the other direction, it increased just twofold.

The low-SDS fraction was further analyzed by ELISA using anti-A $\beta$ antibody $82 \mathrm{E} 1$ for both capture and detection to quantify total oligomeric $A \beta$, including species that may not have been detected by immunoblot. Absent the detergent and denaturing agents used in the Western analysis described earlier in this section, this ELISA method presumably captured $A \beta$ species closer to their native conformation in vivo. The absolute levels of oligomeric $\mathrm{A} \beta$ in this fraction were low, but quantifiable in the $\mathrm{pmol} / \mathrm{L}$ range, increasing $>500$-fold between 3 and 12 months (Figure 5C). The high-SDS fraction was not compatible with antibody binding required for ELISA detection and was not pursued after pilot studies produced no signal, even in tissue from 12-month-old mice.

To determine which oligomeric structures were present in the cortical extracts, dot blot immunodetection was performed using the antibodies A11 to identify nonfibrillar amyloid assemblies and OC to identify prefibrillar 


\section{A Low-SDS extract}

APP/TTA

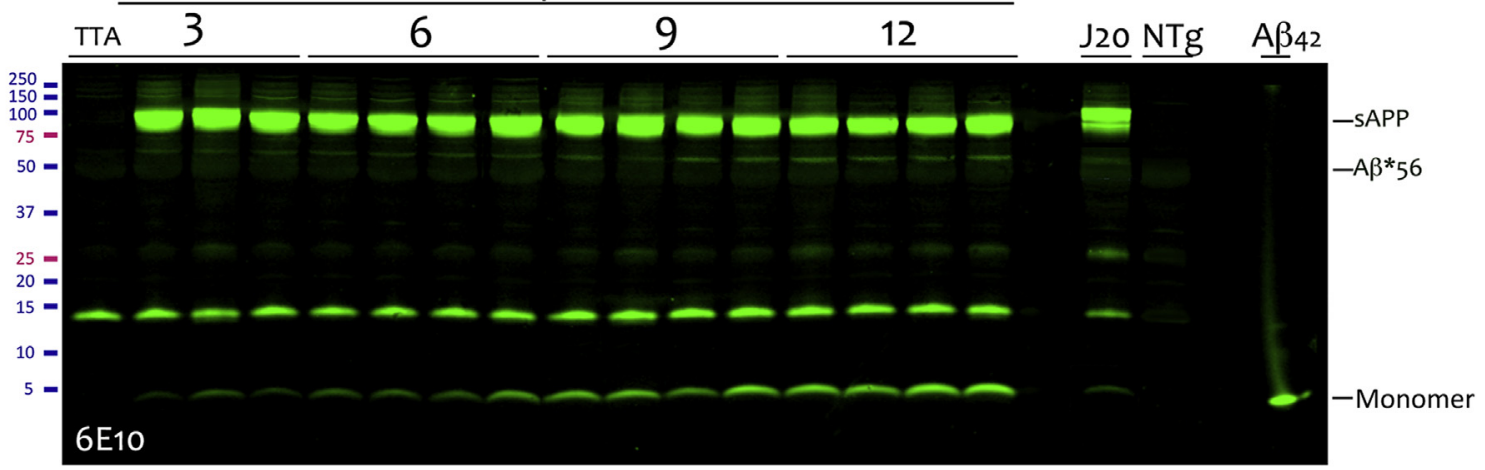

High-SDS extract
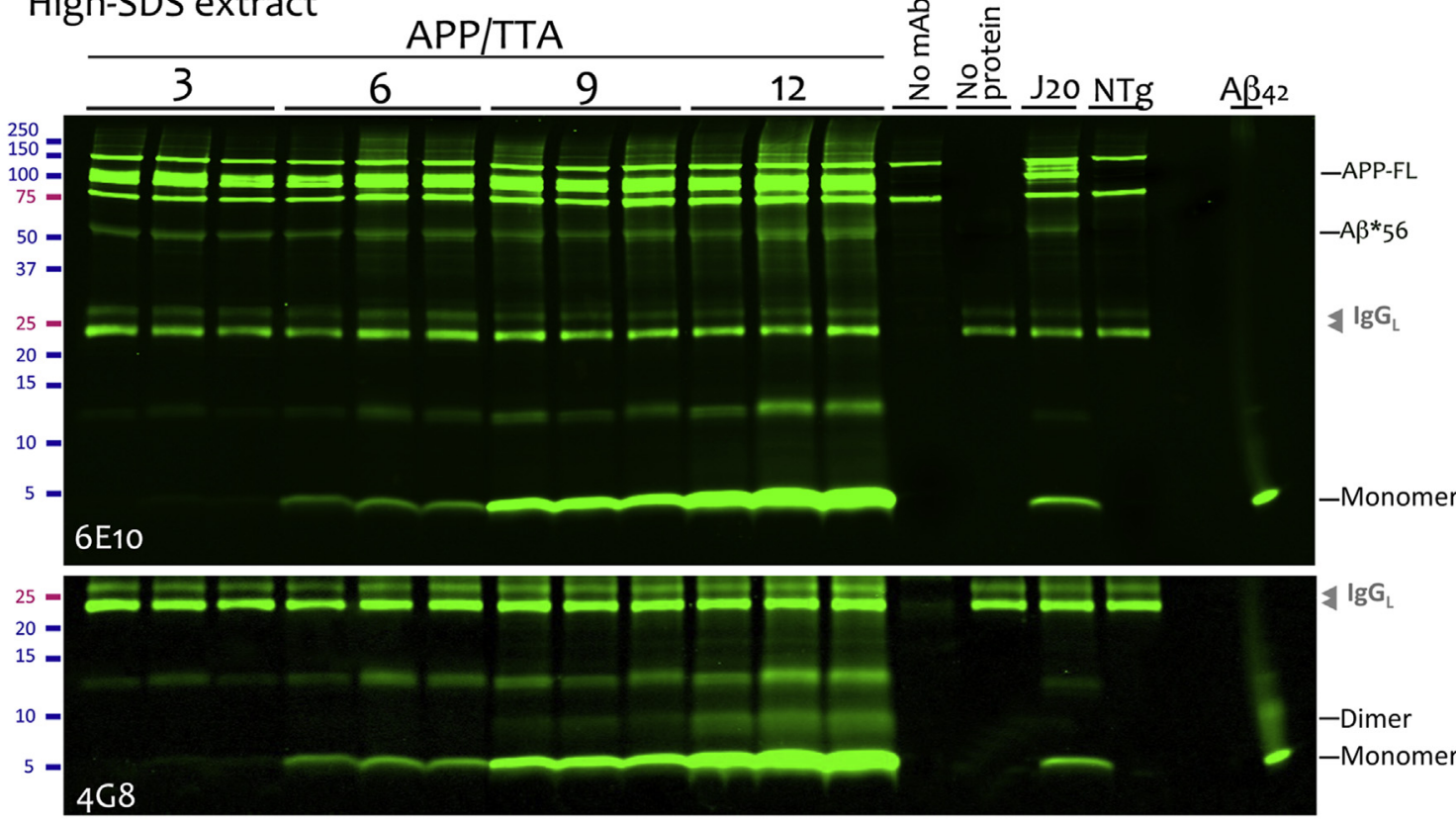

B

IP-Western (high-SDS extract)
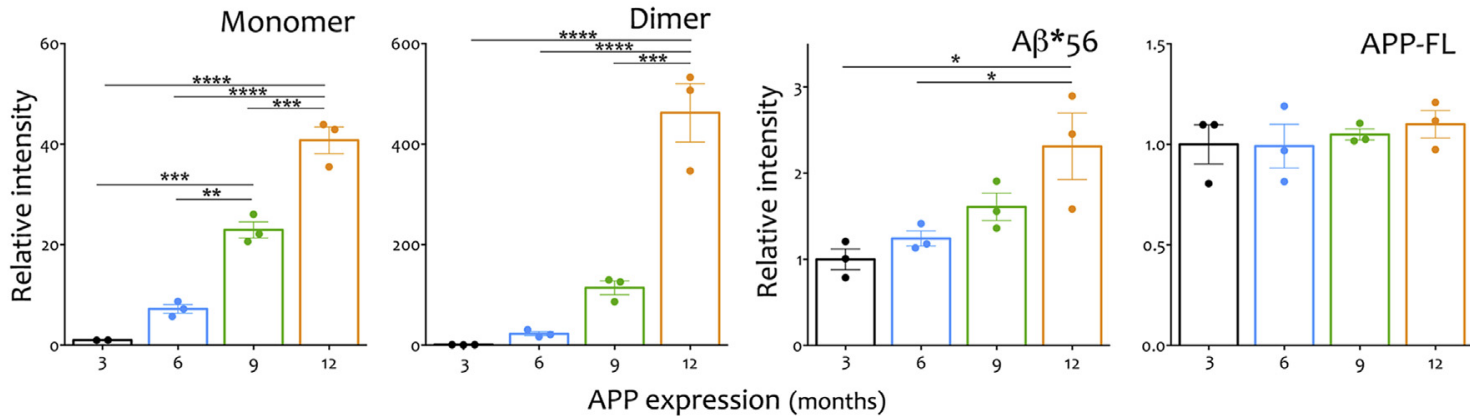

C

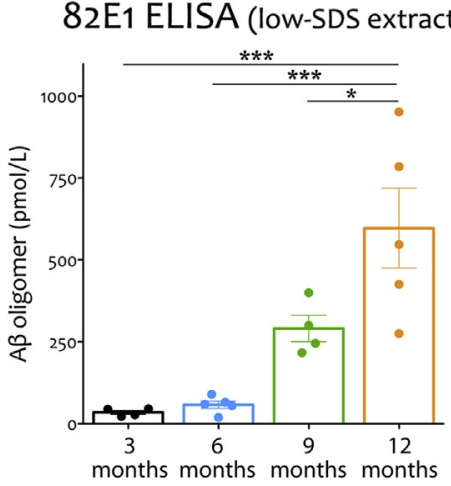

Figure 5 Distinct patterns of A $\beta$ species across different stages of amyloid load. Low- and high-SDS fractions of cortical homogenate were used to characterize the development of oligomeric $A \beta$ species with increasing plaque load. A: Top panel: Immunoblot of the extracellular-enriched low-SDS extract probed with 6 E10 identified $A \beta$ monomer, $A \beta^{\star} 56$, and soluble APP (SAPP). Middle and bottom panels: $4 \mathrm{G} 8$ immunoprecipitation of the membrane-enriched high-SDS extract probed with $6 \mathrm{E} 10$ (middle panel) or 4G8 (bottom panel) identifies A $\beta$ monomer, dimer, $A \beta^{\star} 56$, and full-length APP (APP-FL). B: Monomer and dimer levels were quantified from the $4 \mathrm{G} 8$ immunoprecipitation/immunoblot (A, bottom panel), $A \beta^{\star} 56$, and APPFL from the 4G8 immunoprecipitation/6E10 immunoblot (A, middle panel). All values are normalized to the levels detected in APP/TTA mice at 3 months. The scale of the $y$ axis has been adjusted in each panel to fit the data and varies significantly between graphs. One-way analysis of variance, monomer: $F(3,7)=94.83$, $P<0.0001$; dimer: $\mathrm{F}(3,8)=50.85, P<0.0001 ; \mathrm{A} \beta^{*} 56: \mathrm{F}(3,8)=6.645, P<0.0145$. C: $82 \mathrm{E} 1$ enzymelinked immunosorbent assay (ELISA) provided biochemical confirmation of bona fide oligomeric $A \beta$ in the low-SDS extract. One-way analysis of variance, $\mathrm{F}(3,14)=14.30, P<0.0005$. Graphs indicate significant post hoc comparisons. ${ }^{*} P<0.05,{ }^{* *} P<0.01,{ }^{* *} P<0.001$, and ${ }^{* * * *} P<0.0001$. NTg, nontransgenic. 
A
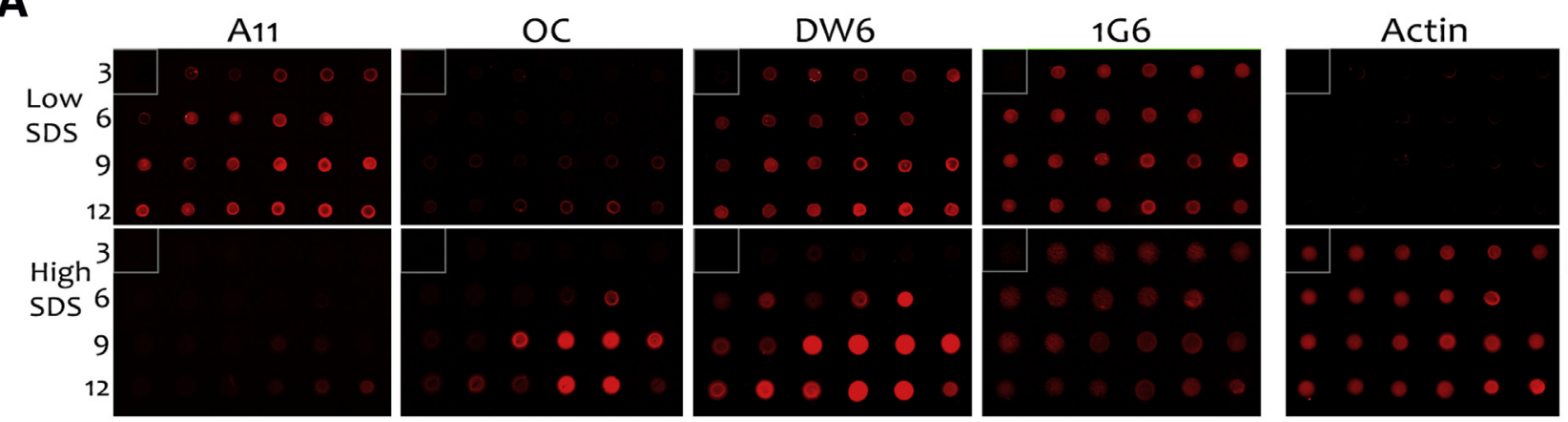

B
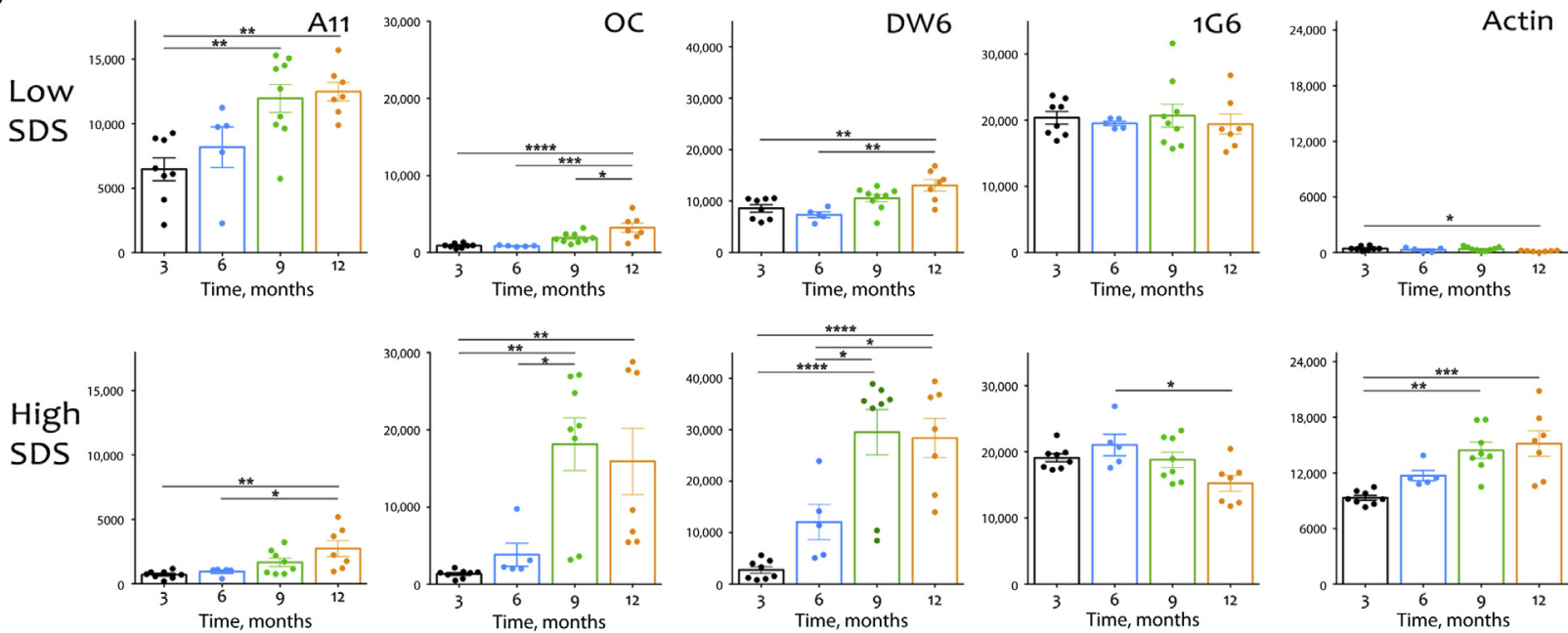

Figure 6 Different oligomeric species show distinct temporal and spatial patterns. A: Low- and high-SDS extracts of cortical tissue, enriched for extracellular and membrane-associated proteins, respectively, were tested by dot blot for oligomeric peptide using antibodies OC and A11. Samples were also probed with DW6 for A 340 and $1 \mathrm{G} 6$ for An-cleaved fragments; actin was used as an internal control. Each panel shows the same subset of cortical extracts, with TTA control extract outlined in the top left corner of each blot (boxed areas). B: Quantitation of signal intensity from dot blots shown in A, expressed in arbitrary units. The $y$ axis varies across antibodies but is consistent between fractions for each. One way analysis of variance, low-SDS: A11: F(3,25) $=8.156$, $P<0.0005 ; \mathrm{OC}: \mathrm{F}(3,24)=11.74, P<0.0001 ; \mathrm{DW} 6: \mathrm{F}(3,25)=7.735, P<0.001 ; 1 \mathrm{G} 6: \mathrm{F}(3,25)=0.1941, P>0.05 ;$ actin: $\mathrm{F}(3,25)=3.015, P<0.05 ;$ high SDS: A11: $\mathrm{F}(3,24)=6.199, P<0.01 ; 0 \mathrm{C}: \mathrm{F}(3,24)=8.504, P=0.0005 ; \mathrm{DW6}: \mathrm{F}(3,24)=15.77, P<0.0001 ; 1 \mathrm{G6}: \mathrm{F}(3,24)=4.202, P<0.05 ;$ actin: $\mathrm{F}(3,24)=9.956, P=0.0002$. Graphs indicate significant post hoc comparisons. $n=53$ and 6 months $(\mathbf{A}) ; n=69$ and 12 months $(\mathbf{A}) .{ }^{*} P<0.05$, $* * P<0.01,{ }^{* * *} P<0.001$, and $* * * * P<0.0001$.

assemblies $^{34}$ (Figure 6). Antibody 1 G6 was also tested to identify noncannonical $\eta$-cleaved APP fragments, including $\mathrm{N}$-terminally extended $\mathrm{A} \beta, \mathrm{C}$-terminal fragment $-\eta$, and $\mathrm{A} \eta^{35,36}$; antibody DW6 to identify $\mathrm{A} \beta 40^{37,38}$; and actin as a control for cellular fractionation and sample loading. This experiment revealed a distinct separation between A11positive nonfibrillar oligomers localized almost exclusively in the low-SDS fraction enriched for extracellular proteins and OC-positive prefibrillar oligomers in the high-SDS fraction enriched for membrane-associated proteins. A11positive species were present by 3 months and increased approximately 2.5 -fold over time. OC-positive species took longer to accrue and then increased more steeply than A11, but were much more variable at late ages. Immunofluorescence for OC was consistent with its extraction into the high-detergent fraction, being found primarily associated with deposited A $\beta$ (Supplemental Figure S3 and
Supplemental Figure S4). The high-detergent membraneassociated fraction also contained more $\mathrm{A} \beta 40$ than the extracellular-enriched low-SDS fraction, and like the signal for OC, increased steeply over time with increasing variability in aged animals. APP $\eta$-fragments detected with 1G6 were present in both extracts, but the amount of these species did not change appreciably with age.

\section{Discussion}

We set out to define the relationship between cognitive performance and $A \beta$ oligomeric species across the span of amyloid burden found in human AD. A mouse model with aggressive $A \beta$ overproduction was used to recapitulate the full spectrum of CERAD staging before reaching midlife. This model allowed us to separate $A \beta$-associated behavioral 
changes from normal aging-related decline and thereby isolate one feature of $\mathrm{AD}$ that is normally indivisible from the other. Biochemical extracts were examined from brain tissue from the behaviorally tested animals seeking specific A $\beta$ conformations that emerged in parallel with cognitive impairment. These efforts yielded several conclusions. First, A $\beta$ pathology alone - in the absence of neurofibrillary tangles, neuronal loss, or systemic aging - can impair spatial learning and short-term memory in mice at plaque loads equivalent to those found in human $\mathrm{AD}$. This finding is consistent with emerging appreciation of psychometric differences between control subjects based on the presence or absence of amyloid positron emission tomography signal, ${ }^{12-19}$ and may prompt a reevaluation of the current biomarker model portraying $A \beta$ as a necessary, but insufficient, player in cognitive decline. ${ }^{9,10}$ Second, different forms of oligomeric $A \beta$ display highly divergent biochemical and temporal patterns of accumulation that may inform the likelihood of a role in cognitive decline.

We undertook this study hoping to identify one or more forms of oligomeric $A \beta$ that tracked with behavioral decline. This has admittedly been an elusive goal in the past and is clearly limited by the techniques available to isolate and detect various $\mathrm{A} \beta$ species. ${ }^{1,2,39,40}$ Multiple approaches were used to identify and measure oligomeric species (ELISA, immunoprecipitation-Western blotting, and dotblot) using antibodies specific for $\mathrm{A} \beta(6 \mathrm{E} 10,4 \mathrm{G} 8,82 \mathrm{E} 1$, and DW6) or quaternary structures shared by oligomers of many pathogenic proteins (A11 and OC). These measures yielded distinct concentration profiles over time, of which the conformations identified by A11 and OC tracked most closely with behavior. Although the increase of A11 and OC oligomers displayed similar temporal profiles, the discrete cellular localization of these two conformations-or more accurately, their distinct biochemical solubility-was an equally striking and informative outcome. A11-positive nonfibrillar aggregates were located almost exclusively in the low-SDS extract enriched for extracellular proteins, whereas OC-positive prefibrillar aggregates predominated in the high-SDS extract enriched for membrane-associated proteins. This complementary localization is consistent with recent work proposing that the two main types of oligomeric $\mathrm{A} \beta$ (type I, preferentially recognized by A11; and type II, preferentially recognized by by OC) have distinct distributions within the brain. ${ }^{41}$ Type II (OC) oligomers were characterized as in-register parallel $\beta$-sheet fibrils that appear with dense core plaques and remain spatially restricted to the immediate vicinity of amyloid deposits. In our hands, aggregates detected by OC were concentrated in the fraction enriched for membraneassociated proteins; this separation may also indicate that high-detergent conditions are needed to solubilize these species. Type I (A11) oligomers, structurally characterized as out-of-register antiparallel $\beta$ sheets, emerge before densecore deposits and spread widely throughout the brain. Despite their low absolute concentration, Liu et $\mathrm{al}^{41}$ suggested that the broad distribution of type I oligomers supported their potential to wreak global network impairment. Consistent with this classification, it was found that the A11-positive species were present from the earliest ages, and their presence in the highly soluble (low-detergent) extract enriched for extracellular proteins would support their dissemenation throughout the cortex. The early increase and late abeyance of A11-positive type I oligomers in this extract appear to most closely parallel spatial deficits, consistent with the possibility that this conformation plays a role in cognitive impairment.

Despite mounting evidence in model systems favoring a role for A11 species, one of the few studies to examine both A11 and OC oligomers in human brain extracts concluded that the fibrillar oligomers detected by $\mathrm{OC}$ were more relevant to cognitive decline in $\mathrm{AD}$ than the prefibrillar species detected by A $11 .{ }^{42}$ In this study, Tomic et al ${ }^{42}$ found that only OC distinguished phosphate-buffered saline brain extracts of $\mathrm{AD}$ subjects from controls. This correlative evidence favoring a role for fibrillar oligomers is countered-or complemented-by experimental manipulations in multiple animal models, suggesting that prefibrillar oligomers recognized by A11 are both necessary and sufficient for cognitive decline. Complementary studies have shown the presence of OC-positive fibrillar oligomers in their native state has little impact on cognitive function. To the first point, Rasool et $\mathrm{al}^{43}$ demonstrated that immunization with a random sequence amyloid oligomer recognized by A11 was sufficient to mitigate cognitive decline in $\operatorname{Tg} 2576$ mice. The same group subsequently showed that passive immunization with A11 itself was sufficient to reverse learning deficits in $3 \times \mathrm{TTg}-\mathrm{AD}$ mice. ${ }^{44}$ Taking the opposite approach, Knight et $\mathrm{al}^{45}$ demonstrated that depleting human intravenous Ig of antibodies against globular $\mathrm{A} \beta$ oligomer prevented rescue of fear conditioning and spontaneous alternation deficits in APP Dutch transgenic mice. Most recently, Amar et al ${ }^{46}$ demonstrated that direct application of purified A11-positive oligomer $A \beta * 56$, but not $A \beta$ dimer or trimer, amplified a CaMKII $\alpha$ signaling cascade, leading to selective tau phosphorylation and mislocalization in primary neurons. These studies support a role for A11 species in circuit dysfunction and cognitive decline, without ruling out the potential contribution of OC-type oligomers. Indeed, Liu et $\mathrm{al}^{41}$ showed that OC oligomers were capable of impairing cognitive performance when exogenously introduced into wild-type rodents. Nevertheless, OC-positive oligomers seem to be functionally inert in situ: the rTg9191 model accumulates substantial amounts of OCpositive type II oligomer without cognitive decline, whereas behavioral impairments in the APP/TTA model studied herein can be rescued by transgene suppression, even while OC oligomers perdure.

Our analysis also identified oligomeric species that tracked poorly with behavioral performance. The most remarkable of these was dimeric $A \beta$, which increased $>20$ fold between 9 and 12 months of age, without any 
substantive change in spatial learning. Several other APP transgenic models display a similar sharp increase in $A \beta$ dimer at high plaque burden, including $\mathrm{J} 20^{47}$ and $3 \times \mathrm{Tg},{ }^{48}$ without a corresponding decrease in functional performance. ${ }^{49}$ On one hand, this may suggest that distinct aggregates promote different stages of cognitive decline, as suggested by previous studies of dimer, trimer, and $A \beta * 56$ in human autopsy material spanning a range of ages and cognitive status. ${ }^{33}$ On the other hand, it may indicate that dimeric $A \beta$ does not have a significant impact on circuit function. Past work argues against this explanation, because human tissue extracts, cerebrospinal fluid, or culture media containing dimeric $\mathrm{A} \beta$ (in addition to $\mathrm{A} \eta^{50}$ ) were sufficient to impair hippocampal synaptic potentiation both in vitro and in vivo. ${ }^{51-53}$ The broader caveat to such dissociative biochemical analyses is that they may not reflect oligomeric A $\beta$ species present in vivo. Using techniques such as size exclusion chromatography ${ }^{54}$ or blue native PAGE, ${ }^{55-57}$ other groups have shown that oligomeric $A \beta$ extracted from human cortex or APP transgenic mouse brain displays a broad size range of many hundred kilodaltons. The same tissue extracts yielded primarily low-n oligomers, such as dimer and trimer on SDS-PAGE, suggesting that either these small $A \beta$ species were present in the brain but not compatible with the conditions used for native PAGE or they arose through dissolution of larger $A \beta$ species on exposure to SDS buffer. Our findings herein nevertheless suggest that SDS-stable $A \beta$ becomes increasingly prone to appear in dimeric form with age, while exerting no commensurate impact on cognitive function. Of course, an alternative possibility is that behavioral testing in mice may simply lack adequate dynamic range to detect continued decline. New approaches for chemically stabilizing specific oligomer species will resolve many of these current uncertainties by allowing explicit attribution of structurefunction relationships in vitro and in vivo. ${ }^{58,59}$

$\mathrm{A} \beta$ species was focused on as the most likely cause of cognitive decline in mice, yet the possibility that other APP fragments or even full-length protein itself may contribute to their behavioral phenotype cannot be ruled out. Aside from $\mathrm{A} \beta$, none of the other processed derivatives accumulate over time, and transgenic APP levels remain stable with age. Nevertheless, continuous overexposure to one or more of these fragments, or to the persistent imbalance of $\alpha$ - and $\beta$ processed derivatives, might accrue physiological consequences that are not observed acutely. These fragments need not act alone-physical damage caused by the formation of amyloid plaques might render neighboring neurons more susceptible to the effects of full-length APP or its nonamyloid derivatives. Our own past work with the APP/TTA model shows that certain age-associated phenotypes are dependent on continued APP production but not on A $\beta$ release. ${ }^{60}$ Certainly, there are documented neurophysiological effects ascribed to nearly all APP cleavage fragments. ${ }^{61}$ However, rather than being nonphysiological, elevated APP expression in these mice may actually be relevant to $\mathrm{AD}$ because recent work has found significant copy number mosaicism in the APP gene. Single neurons isolated at autopsy from subjects with sporadic AD carried, on average, twice the normal content of APP DNA, and several cases displayed copy number changes of fourfold to sixfold over controls. ${ }^{62}$ The resulting APP expression expected from these genomic duplications would magnify production of multiple APP fragments, including A $\beta$.

A second assumption made in interpreting these data is that the cognitive impairments observed were attributable to the direct influence of $A \beta$ aggregates on neural function. In truth, the formation of $A \beta$ plaques evokes a myriad of secondary consequences that may also contribute to cognitive impairment. ${ }^{63,64}$ Activated microglia and hypertrophic astrocytes surrounding amyloid plaques secrete a mixture of inflammatory cytokines, chemokines, and complement factors sufficient to severely curtail synaptic plasticity. ${ }^{65-67}$ Consistent with this mechanism, genetic reduction or pharmacologic inhibition of IL-12, IL-23, and C3a alleviates cognitive decline in various APP transgenic mice. ${ }^{68,69}$ Microglia may further contribute to neuronal dysfunction through pathologic reactivation of synaptic pruning in response to $A \beta$ exposure. ${ }^{70}$ Astrocyte dysfunction secondary to $A \beta$ exposure further weakens the synapse through impaired glutamate uptake and aberrant calcium signaling. ${ }^{71}$ Neurons themselves are also vulnerable to dystrophic swelling on contact with deposited amyloid, which leads to neuritic degeneration that physically disconnects affected neural circuits. ${ }^{72}$ Thus, $A \beta$ accumulation likely acts through multiple cell types and pathologic mechanisms to impair cognitive function, each potentially susceptible to distinct $\mathrm{A} \beta$ species.

Studies such as this and many others before show that some aspect of prolonged APP overexpression-most likely the accumulation of $A \beta$-causes substantial impairment of cognitive function in the absence of neurofibrillary tangles or overt neurodegneration. ${ }^{49}$ Yet, the current clinical picture of $\mathrm{AD}$ posits that $\mathrm{A} \beta$ accumulation begins and ends long before any change in cognitive status occurs. ${ }^{9}$ At face value, this difference suggests that brain function in mice is far more vulnerable to $A \beta$ aggregation than in humans. Certainly, mouse models raised in the laboratory lack the cumulative benefits afforded by environmental factors, such as education, exercise, and social interaction, that can mitigate functional decline of $\mathrm{AD}$ in human studies. ${ }^{73-78}$ However, an alternative interpretation of this apparent mouse-human discrepancy is that $A \beta$ may simply have more subtle effects on human cognitive function than in mice. Consistent with this idea, studies of cognitively normal cohorts have begun to identify significant functional differences between amyloid-positive and amyloid-negative subjects. ${ }^{79-83}$ The most susceptible tasks were episodic memory, working memory, and visuospatial performance: all early hallmarks of AD, and each affected in APP/TTA mice. ${ }^{24,69,84,85}$ Rather than being necessary but insufficient for $\mathrm{AD}$ progression, amyloid pathology may herald the 
presence of smaller $A \beta$ species that have already begun to subtly erode cognitive function.

\section{Acknowledgments}

We thank Bryan Song and Yuanyuan Zhang for animal care, Rich Paylor for advice on behavioral testing, and Charlie Glabe and Rakez Kayed for sharing nonfibrillar $A \beta$ oligomer and prefibrillar antibodies.

A.C.A.C., S.W.F., S.E.L., and J.L.J. designed the experiments; A.C.A.C., S.W.F., and M.A.S. performed the experiments; A.C.A.C., S.W.F., R.R., M.A.S., S.E.L., and J.L.J. analyzed the data; J.C.T. and O.P. provided staged autopsy material; A.C.A.C., S.E.L., and J.L.J. wrote the article.

\section{Supplemental Data}

Supplemental material for this article can be found at https://doi.org/10.1016/j.ajpath.2017.11.011.

\section{References}

1. Lesne SE: Toxic oligomer species of amyloid-beta in Alzheimer's disease, a timing issue. Swiss Med Wkly 2014, 144:w14021

2. Benilova I, Karran E, De Strooper B: The toxic Abeta oligomer and Alzheimer's disease: an emperor in need of clothes. Nat Neurosci 2012, 15:349-357

3. Nelson PT, Alafuzoff I, Bigio EH, Bouras C, Braak H, Cairns NJ, et al: Correlation of Alzheimer disease neuropathologic changes with cognitive status: a review of the literature. J Neuropathol Exp Neurol 2012, 71:362-381

4. Blessed G, Tomlinson BE, Roth M: The association between quantitative measures of dementia and of senile change in the cerebral grey matter of elderly subjects. Br J Psychiatry 1968, 114:797-811

5. Terry RD, Masliah E, Salmon DP, Butters N, DeTeresa R, Hill R, Hansen LA, Katzman R: Physical basis of cognitive alterations in Alzheimer's disease: synapse loss is the major correlate of cognitive impairment. Ann Neurol 1991, 30:572-580

6. Arriagada PV, Growdon JH, Hedley-Whyte ET, Hyman BT: Neurofibrillary tangles but not senile plaques parallel duration and severity of Alzheimer's disease. Neurology 1992, 42:631-639

7. Berg L, McKeel DW Jr, Miller JP, Baty J, Morris JC: Neuropathological indexes of Alzheimer's disease in demented and nondemented persons aged 80 years and older. Arch Neurol 1993, 50:349-358

8. McKee AC, Kosik KS, Kowall NW: Neuritic pathology and dementia in Alzheimer's disease. Ann Neurol 1991, 30:156-165

9. Jack CR Jr, Knopman DS, Jagust WJ, Petersen RC, Weiner MW Aisen PS, Shaw LM, Vemuri P, Wiste HJ, Weigand SD, Lesnick TG Pankratz VS, Donohue MC, Trojanowski JQ: Tracking pathophysiological processes in Alzheimer's disease: an updated hypothetica model of dynamic biomarkers. Lancet Neurol 2013, 12:207-216

10. Jack CR Jr, Knopman DS, Jagust WJ, Shaw LM, Aisen PS, Weiner MW, Petersen RC, Trojanowski JQ: Hypothetical model of dynamic biomarkers of the Alzheimer's pathological cascade. Lancet Neurol 2010, 9:119-128

11. Ashe KH, Zahs KR: Probing the biology of Alzheimer's disease in mice. Neuron 2010, 66:631-645

12. Rosenberg PB, Wong DF, Edell SL, Ross JS, Joshi AD, Brasic JR, Zhou Y, Raymont V, Kumar A, Ravert HT, Dannals RF, Pontecorvo MJ, Skovronsky DM, Lyketsos CG: Cognition and amyloid load in Alzheimer disease imaged with florbetapir F 18(AV45) positron emission tomography. Am J Geriatr Psychiatry 2013, 21 272-278

13. Kawas CH, Greenia DE, Bullain SS, Clark CM, Pontecorvo MJ, Joshi AD, Corrada MM: Amyloid imaging and cognitive decline in nondemented oldest-old: the 90+ Study. Alzheimers Dement 2013,9: 199-203

14. Kennedy KM, Rodrigue KM, Devous MD Sr, Hebrank AC, Bischof GN, Park DC: Effects of beta-amyloid accumulation on neural function during encoding across the adult lifespan. Neuroimage 2012, 62:1-8

15. Rodrigue KM, Kennedy KM, Devous MD Sr, Rieck JR, Hebrank AC, Diaz-Arrastia R, Mathews D, Park DC: beta-Amyloid burden in healthy aging: regional distribution and cognitive consequences. Neurology 2012, 78:387-395

16. Boyle PA, Yu L, Wilson RS, Schneider JA, Bennett DA: Relation of neuropathology with cognitive decline among older persons without dementia. Front Aging Neurosci 2013, 5:50

17. Lim YY, Ellis KA, Pietrzak RH, Ames D, Darby D, Harrington K, Martins RN, Masters CL, Rowe C, Savage G, Szoeke C, Villemagne VL, Maruff P: Stronger effect of amyloid load than APOE genotype on cognitive decline in healthy older adults. Neurology 2012, 79:1645-1652

18. Drzezga A, Becker JA, Van Dijk KR, Sreenivasan A, Talukdar T, Sullivan C, Schultz AP, Sepulcre J, Putcha D, Greve D, Johnson KA, Sperling RA: Neuronal dysfunction and disconnection of cortical hubs in non-demented subjects with elevated amyloid burden. Brain 2011, 134:1635-1646

19. Chetelat G, Villemagne VL, Pike KE, Ellis KA, Bourgeat P, Jones G, O'Keefe GJ, Salvado O, Szoeke C, Martins RN, Ames D, Masters CL, Rowe CC: Independent contribution of temporal betaamyloid deposition to memory decline in the pre-dementia phase of Alzheimer's disease. Brain 2011, 134:798-807

20. Jankowsky JL, Slunt HH, Gonzales V, Savonenko AV, Wen JC, Jenkins NA, Copeland NG, Younkin LH, Lester HA, Younkin SG, Borchelt DR: Persistent amyloidosis following suppression of $A \beta$ production in a transgenic model of Alzheimer's disease. PLoS Med $2005,2: \mathrm{e} 355$

21. Mayford M, Bach ME, Huang YY, Wang L, Hawkins RD Kandel ER: Control of memory formation through regulated expression of a CaMKII transgene. Science 1996, 274:1678-1683

22. Han HJ, Allen CC, Buchovecky CM, Yetman MJ, Born HA, Marin MA, Rodgers SP, Song BJ, Lu HC, Justice MJ, Probst FJ, Jankowsky JL: Strain background influences neurotoxicity and behavioral abnormalities in mice expressing the tetracycline transactivator. J Neurosci 2012, 32:10574-10586

23. Rodgers SP, Born HA, Das P, Jankowsky JL: Transgenic APP expression during postnatal development causes persistent locomotor hyperactivity in the adult. Mol Neurodegener 2012, 7:28

24. Fowler SW, Chiang AC, Savjani RR, Larson ME, Sherman MA Schuler DR, Cirrito JR, Lesne SE, Jankowsky JL: Genetic modulation of soluble abeta rescues cognitive and synaptic impairment in a mouse model of Alzheimer's disease. J Neurosci 2014, 34 $7871-7885$

25. Brody DL, Holtzman DM: Morris water maze search strategy analysis in PDAPP mice before and after experimental traumatic brain injury. Exp Neurol 2006, 197:330-340

26. Mirra SS, Heyman A, McKeel D, Sumi SM, Crain BJ, Brownlee LM, Vogel FS, Hughes JP, van Belle G, Berg L: The Consortium to Establish a Registry for Alzheimer's Disease (CERAD), part II: standardization of the neuropathologic assessment of Alzheimer's disease. Neurology 1991, 41:479-486

27. Sherman MA, Lesne SE: Detecting abeta*56 oligomers in brain tissues. Methods Mol Biol 2011, 670:45-56

28. Lesne S, Koh MT, Kotilinek L, Kayed R, Glabe CG, Yang A, Gallagher M, Ashe KH: A specific amyloid-beta protein assembly in the brain impairs memory. Nature 2006, 440:352-357 
29. King DL, Arendash GW: Behavioral characterization of the Tg 2576 transgenic model of Alzheimer's disease through 19 months. Physiol Behav 2002, 75:627-642

30. de Fiebre NC, Sumien N, Forster MJ, de Fiebre CM: Spatial learning and psychomotor performance of C57BL/6 mice: age sensitivity and reliability of individual differences. Age (Dordr) 2006, 28:235-253

31. Harburger LL, Lambert TJ, Frick KM: Age-dependent effects of environmental enrichment on spatial reference memory in male mice. Behav Brain Res 2007, 185:43-48

32. Zhao X, Rosenke R, Kronemann D, Brim B, Das SR, Dunah AW, Magnusson KR: The effects of aging on N-methyl-D-aspartate receptor subunits in the synaptic membrane and relationships to longterm spatial memory. Neuroscience 2009, 162:933-945

33. Lesne SE, Sherman MA, Grant M, Kuskowski M, Schneider JA, Bennett DA, Ashe KH: Brain amyloid-beta oligomers in ageing and Alzheimer's disease. Brain 2013, 136:1383-1398

34. Kayed R, Head E, Thompson JL, McIntire TM, Milton SC, Cotman CW, Glabe CG: Common structure of soluble amyloid oligomers implies common mechanism of pathogenesis. Science 2003, 300:486-489

35. Willem M, Tahirovic S, Busche MA, Ovsepian SV, Chafai M, Kootar S, Hornburg D, Evans LD, Moore S, Daria A, Hampel H, Muller V, Giudici C, Nuscher B, Wenninger-Weinzierl A, Kremmer E, Heneka MT, Thal DR, Giedraitis V, Lannfelt L, Muller U, Livesey FJ, Meissner F, Herms J, Konnerth A, Marie H, Haass C: eta-Secretase processing of APP inhibits neuronal activity in the hippocampus. Nature 2015, 526:443-447

36. Szczepankiewicz O, Linse B, Meisl G, Thulin E, Frohm B, Sala Frigerio C, Colvin MT, Jacavone AC, Griffin RG, Knowles T, Walsh DM, Linse S: N-terminal extensions retard Abeta42 fibril formation but allow cross-seeding and coaggregation with Abeta42. J Am Chem Soc 2015, 137:14673-14685

37. Meyer-Luehmann M, Coomaraswamy J, Bolmont T, Kaeser S, Schaefer C, Kilger E, Neuenschwander A, Abramowski D, Frey P, Jaton AL, Vigouret JM, Paganetti P, Walsh DM, Mathews PM, Ghiso J, Staufenbiel M, Walker LC, Jucker M: Exogenous induction of cerebral beta-amyloidogenesis is governed by agent and host. Science 2006, 313:1781-1784

38. Larson M, Sherman MA, Amar F, Nuvolone M, Schneider JA, Bennett DA, Aguzzi A, Lesne SE: The complex PrP(c)-Fyn couples human oligomeric Abeta with pathological tau changes in Alzheimer's disease. J Neurosci 2012, 32:16857-16871a

39. Jarosz-Griffiths HH, Noble E, Rushworth JV, Hooper NM: Amyloidbeta receptors: the good, the bad, and the prion protein. J Biol Chem 2016, 291:3174-3183

40. Broersen K, Rousseau F, Schymkowitz J: The culprit behind amyloid beta peptide related neurotoxicity in Alzheimer's disease: oligomer size or conformation? Alzheimers Res Ther 2010, 2:12

41. Liu P, Reed MN, Kotilinek LA, Grant MK, Forster CL, Qiang W, Shapiro SL, Reichl JH, Chiang AC, Jankowsky JL, Wilmot CM, Cleary JP, Zahs KR, Ashe KH: Quaternary structure defines a large class of amyloid-beta oligomers neutralized by sequestration. Cell Rep 2015, 11:1760-1771

42. Tomic JL, Pensalfini A, Head E, Glabe CG: Soluble fibrillar oligomer levels are elevated in Alzheimer's disease brain and correlate with cognitive dysfunction. Neurobiol Dis 2009, 35:352-358

43. Rasool S, Albay R 3rd, Martinez-Coria H, Breydo L, Wu J, Milton S, Misra S, Tran A, Pensalfini A, Laferla F, Kayed R, Glabe CG: Vaccination with a non-human random sequence amyloid oligomer mimic results in improved cognitive function and reduced plaque deposition and micro hemorrhage in $\operatorname{Tg} 2576$ mice. Mol Neurodegener 2012, 7:37

44. Rasool S, Martinez-Coria H, Wu JW, LaFerla F, Glabe CG: Systemic vaccination with anti-oligomeric monoclonal antibodies improves cognitive function by reducing Abeta deposition and tau pathology in 3xTg-AD mice. J Neurochem 2013, 126:473-482
45. Knight EM, Kim SH, Kottwitz JC, Hatami A, Albay R, Suzuki A, Lublin A, Alberini CM, Klein WL, Szabo P, Relkin NR, Ehrlich M, Glabe CG, Gandy S, Steele JW: Effective anti-Alzheimer Abeta therapy involves depletion of specific Abeta oligomer subtypes. Neurol Neuroimmunol Neuroinflamm 2016, 3:e237

46. Amar F, Sherman MA, Rush T, Larson M, Boyle G, Chang L, Gotz J, Buisson A, Lesne SE: The amyloid-beta oligomer Abeta*56 induces specific alterations in neuronal signaling that lead to tau phosphorylation and aggregation. Sci Signal 2017, 10:eaal2021

47. Shankar GM, Leissring MA, Adame A, Sun X, Spooner E, Masliah E, Selkoe DJ, Lemere CA, Walsh DM: Biochemical and immunohistochemical analysis of an Alzheimer's disease mouse model reveals the presence of multiple cerebral Abeta assembly forms throughout life. Neurobiol Dis 2009, 36:293-302

48. Oddo S, Caccamo A, Tran L, Lambert MP, Glabe CG, Klein WL, LaFerla FM: Temporal profile of amyloid-beta (Abeta) oligomerization in an in vivo model of Alzheimer disease: a link between Abeta and tau pathology. J Biol Chem 2006, 281:1599-1604

49. Webster SJ, Bachstetter AD, Nelson PT, Schmitt FA, Van Eldik LJ: Using mice to model Alzheimer's dementia: an overview of the clinical disease and the preclinical behavioral changes in 10 mouse models. Front Genet 2014, 5:88

50. Welzel AT, Maggio JE, Shankar GM, Walker DE, Ostaszewski BL, Li S, Klyubin I, Rowan MJ, Seubert P, Walsh DM, Selkoe DJ: Secreted amyloid beta-proteins in a cell culture model include $\mathrm{N}$ terminally extended peptides that impair synaptic plasticity. Biochemistry 2014, 53:3908-3921

51. Klyubin I, Betts V, Welzel AT, Blennow K, Zetterberg H, Wallin A, Lemere CA, Cullen WK, Peng Y, Wisniewski T, Selkoe DJ, Anwyl R, Walsh DM, Rowan MJ: Amyloid beta protein dimercontaining human CSF disrupts synaptic plasticity: prevention by systemic passive immunization. J Neurosci 2008, 28:4231-4237

52. Klyubin I, Walsh DM, Lemere CA, Cullen WK, Shankar GM, Betts V, Spooner ET, Jiang L, Anwyl R, Selkoe DJ, Rowan MJ: Amyloid beta protein immunotherapy neutralizes Abeta oligomers that disrupt synaptic plasticity in vivo. Nat Med 2005, 11:556-561

53. Shankar GM, Li S, Mehta TH, Garcia-Munoz A, Shepardson NE, Smith I, Brett FM, Farrell MA, Rowan MJ, Lemere CA, Regan CM, Walsh DM, Sabatini BL, Selkoe DJ: Amyloid-beta protein dimers isolated directly from Alzheimer's brains impair synaptic plasticity and memory. Nat Med 2008, 14:837-842

54. Esparza TJ, Zhao H, Cirrito JR, Cairns NJ, Bateman RJ, Holtzman DM, Brody DL: Amyloid-beta oligomerization in Alzheimer dementia versus high-pathology controls. Ann Neurol 2013, $73: 104-119$

55. Upadhaya AR, Lungrin I, Yamaguchi H, Fandrich M, Thal DR: High-molecular weight Abeta oligomers and protofibrils are the predominant Abeta species in the native soluble protein fraction of the AD brain. J Cell Mol Med 2012, 16:287-295

56. Rijal Upadhaya A, Capetillo-Zarate E, Kosterin I, Abramowski D, Kumar S, Yamaguchi H, Walter J, Fandrich M, Staufenbiel M, Thal DR: Dispersible amyloid beta-protein oligomers, protofibrils, and fibrils represent diffusible but not soluble aggregates: their role in neurodegeneration in amyloid precursor protein (APP) transgenic mice. Neurobiol Aging 2012, 33:2641-2660

57. Klementieva O, Willen K, Martinsson I, Israelsson B, Engdahl A, Cladera J, Uvdal P, Gouras GK: Pre-plaque conformational changes in Alzheimer's disease-linked Abeta and APP. Nat Commun 2017, 8: 14726

58. Hayden EY, Conovaloff JL, Mason A, Bitan G, Teplow DB: Preparation of pure populations of covalently stabilized amyloid betaprotein oligomers of specific sizes. Anal Biochem 2017, 518:78-85

59. Muller-Schiffmann A, Andreyeva A, Horn AH, Gottmann K, Korth C, Sticht H: Molecular engineering of a secreted, highly homogeneous, and neurotoxic abeta dimer. ACS Chem Neurosci 2011, $2: 242-248$ 
60. Born HA, Kim JY, Savjani RR, Das P, Dabaghian YA, Guo Q, Yoo JW, Schuler DR, Cirrito JR, Zheng H, Golde TE, Noebels JL, Jankowsky JL: Genetic suppression of transgenic APP rescues hypersynchronous network activity in a mouse model of Alzheimer's disease. J Neurosci 2014, 34:3826-3840

61. Zheng H, Koo EH: Biology and pathophysiology of the amyloid precursor protein. Mol Neurodegener 2011, 6:27

62. Bushman DM, Kaeser GE, Siddoway B, Westra JW, Rivera RR, Rehen SK, Yung YC, Chun J: Genomic mosaicism with increased amyloid precursor protein (APP) gene copy number in single neurons from sporadic Alzheimer's disease brains. Elife 2015, 4:e05116

63. Heneka MT, Carson MJ, El Khoury J, Landreth GE, Brosseron F, Feinstein DL, et al: Neuroinflammation in Alzheimer's disease. Lancet Neurol 2015, 14:388-405

64. De Strooper B, Karran E: The cellular phase of Alzheimer's disease. Cell 2016, 164:603-615

65. Lynch MA: Neuroinflammatory changes negatively impact on LTP: a focus on IL-1beta. Brain Res 2015, 1621:197-204

66. Williamson LL, Bilbo SD: Chemokines and the hippocampus: a new perspective on hippocampal plasticity and vulnerability. Brain Behav Immun 2013, 30:186-194

67. Yirmiya R, Goshen I: Immune modulation of learning, memory, neural plasticity and neurogenesis. Brain Behav Immun 2011, 25:181-213

68. Vom Berg J, Prokop S, Miller KR, Obst J, Kalin RE, LopateguiCabezas I, Wegner A, Mair F, Schipke CG, Peters O, Winter Y, Becher B, Heppner FL: Inhibition of IL-12/IL-23 signaling reduces Alzheimer's disease-like pathology and cognitive decline. Nat Med 2012, 18:1812-1819

69. Lian H, Yang L, Cole A, Sun L, Chiang AC, Fowler SW, Shim DJ, Rodriguez-Rivera J, Taglialatela G, Jankowsky JL, Lu HC, Zheng H: NFkappaB-activated astroglial release of complement C3 compromises neuronal morphology and function associated with Alzheimer's disease. Neuron 2015, 85:101-115

70. Hong S, Beja-Glasser VF, Nfonoyim BM, Frouin A, Li S, Ramakrishnan S, Merry KM, Shi Q, Rosenthal A, Barres BA, Lemere CA, Selkoe DJ, Stevens B: Complement and microglia mediate early synapse loss in Alzheimer mouse models. Science 2016, 352:712-716

71. Rudy CC, Hunsberger HC, Weitzner DS, Reed MN: The role of the tripartite glutamatergic synapse in the pathophysiology of Alzheimer's disease. Aging Dis 2015, 6:131-148

72. Vickers JC, King AE, Woodhouse A, Kirkcaldie MT, Staal JA, McCormack GH, Blizzard CA, Musgrove RE, Mitew S, Liu Y, Chuckowree JA, Bibari O, Dickson TC: Axonopathy and cytoskeletal disruption in degenerative diseases of the central nervous system. Brain Res Bull 2009, 80:217-223

73. Stern Y: Cognitive reserve in ageing and Alzheimer's disease. Lancet Neurol 2012, 11:1006-1012

74. Rentz DM, Locascio JJ, Becker JA, Moran EK, Eng E, Buckner RL, Sperling RA, Johnson KA: Cognition, reserve, and amyloid deposition in normal aging. Ann Neurol 2010, 67:353-364
75. Vemuri P, Weigand SD, Przybelski SA, Knopman DS, Smith GE, Trojanowski JQ, Shaw LM, Decarli CS, Carmichael O, Bernstein MA, Aisen PS, Weiner M, Petersen RC, Jack CR Jr; Alzheimer's Disease Neuroimaging Initiative: Cognitive reserve and Alzheimer's disease biomarkers are independent determinants of cognition. Brain 2011, 134:1479-1492

76. Roe CM, Mintun MA, D’Angelo G, Xiong C, Grant EA, Morris JC: Alzheimer disease and cognitive reserve: variation of education effect with carbon 11-labeled Pittsburgh Compound B uptake. Arch Neurol 2008, 65:1467-1471

77. Vemuri P, Lesnick TG, Przybelski SA, Knopman DS, Roberts RO, Lowe VJ, Kantarci K, Senjem ML, Gunter JL, Boeve BF, Petersen RC, Jack CR Jr: Effect of lifestyle activities on Alzheimer disease biomarkers and cognition. Ann Neurol 2012, 72:730-738

78. Kemppainen NM, Aalto S, Karrasch M, Nagren K, Savisto N, Oikonen V, Viitanen M, Parkkola R, Rinne JO: Cognitive reserve hypothesis: Pittsburgh Compound B and fluorodeoxyglucose positron emission tomography in relation to education in mild Alzheimer's disease. Ann Neurol 2008, 63:112-118

79. Monsell SE, Mock C, Hassenstab J, Roe CM, Cairns NJ, Morris JC, Kukull W: Neuropsychological changes in asymptomatic persons with Alzheimer disease neuropathology. Neurology 2014, 83:434-440

80. Lim YY, Maruff P, Pietrzak RH, Ellis KA, Darby D, Ames D, Harrington K, Martins RN, Masters CL, Szoeke C, Savage G, Villemagne VL, Rowe CC: Abeta and cognitive change: examining the preclinical and prodromal stages of Alzheimer's disease. Alzheimers Dement 2014, 10:743-751.e1

81. Sperling RA, Johnson KA, Doraiswamy PM, Reiman EM, Fleisher AS, Sabbagh MN, Sadowsky CH, Carpenter A, Davis MD, Lu M, Flitter M, Joshi AD, Clark CM, Grundman M, Mintun MA, Skovronsky DM, Pontecorvo MJ; AV45-A05 Study Group: Amyloid deposition detected with florbetapir F 18 ((18)F-AV-45) is related to lower episodic memory performance in clinically normal older individuals. Neurobiol Aging 2013, 34:822-831

82. Pike KE, Ellis KA, Villemagne VL, Good N, Chetelat G, Ames D, Szoeke C, Laws SM, Verdile G, Martins RN, Masters CL, Rowe CC: Cognition and beta-amyloid in preclinical Alzheimer's disease: data from the AIBL study. Neuropsychologia 2011, 49: $2384-2390$

83. Pike KE, Savage G, Villemagne VL, Ng S, Moss SA, Maruff P, Mathis CA, Klunk WE, Masters CL, Rowe CC: Beta-amyloid imaging and memory in non-demented individuals: evidence for preclinical Alzheimer's disease. Brain 2007, 130:2837-2844

84. Zhao R, Fowler SW, Chiang AC, Ji D, Jankowsky JL: Impairments in experience-dependent scaling and stability of hippocampal place fields limit spatial learning in a mouse model of Alzheimer's disease. Hippocampus 2014, 24:963-978

85. Melnikova T, Fromholt S, Kim H, Lee D, Xu G, Price A, Moore BD, Golde TE, Felsenstein KM, Savonenko A, Borchelt DR: Reversible pathologic and cognitive phenotypes in an inducible model of Alzheimer-amyloidosis. J Neurosci 2013, 33:3765-3779 